Portland State University

PDXScholar

$12-3-1980$

\title{
A Cognitive-Behavioral Approach to the Control of Dream Content
}

Gary Nick Dean Lehto

Portland State University

Follow this and additional works at: https://pdxscholar.library.pdx.edu/open_access_etds

Part of the Cognitive Psychology Commons

Let us know how access to this document benefits you.

\section{Recommended Citation}

Lehto, Gary Nick Dean, "A Cognitive-Behavioral Approach to the Control of Dream Content" (1980).

Dissertations and Theses. Paper 3054.

https://doi.org/10.15760/etd.3049

This Thesis is brought to you for free and open access. It has been accepted for inclusion in Dissertations and Theses by an authorized administrator of PDXScholar. Please contact us if we can make this document more accessible: pdxscholar@pdx.edu. 
AN ABSTRACT OF THE THESIS OF Gary Nick Dean Lehto for the Master of Science in Psychology presented December 3, 1980 Title: A Cognitive-Behavioral Approach to the Control of Dream Content.

APDROVED BY MEMBERS OF THE THESIS COMMITTEE:
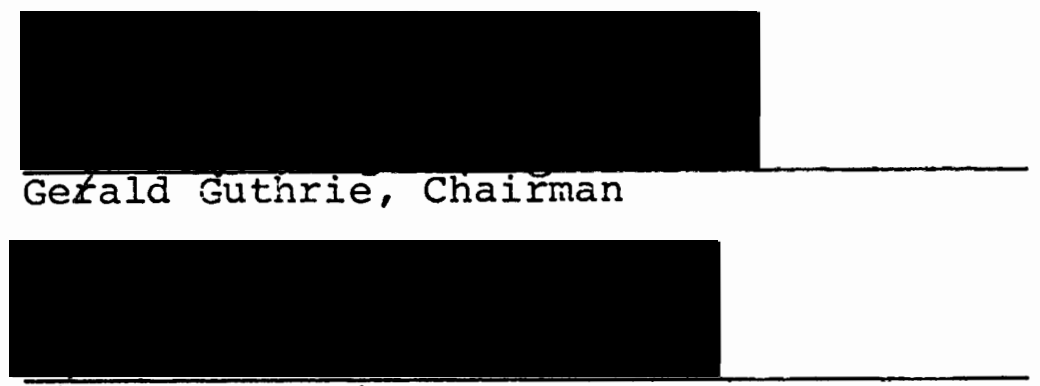

Milton K. Davis

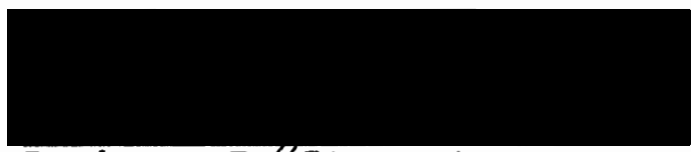

Barbara j. Stewart

A cognitive-behavioral technique for developing dream control was examined. Twenty paid subjects were randomly assigned to either an attention-placebo control group or a cognitive-behavioral training group. Subjects met in the respective groups for a total of three hours of "training". Subjects in the actual training group were presented with a self-instruction sequence to practice and use in attempting to manipulate aream content. The control group subjects met to only discuss dreams and dreaming and were given no specific instruction in content 
control. After completion of the training, each subject individually spent two consecutive nights in a sleep laboratory. The first night of sleep served as an adaptation night, and the second night constituted the posttest portion of the experiment. Prior to going to sleep on the posttest night, all subjects were randomly assigned one of five possible topics to dream about throughout the night and were awakened during every REMP in order to provide a dream report. Eighty-one reports were obtained and given to two independent, "blind" judges for scoring. These judges were requested to match each report with the appropriate topic, evaluate the degree of control present, and rate each report on a measure of dream-like quality.

Dream control was operationally defined as the number of correct report-topic matches (NCM) and the proportion of correct report-topic matches (PCM) agreed upon by both judges. Degree of control was defined in four ways: the number of airect and/or indirect references to the assigned topic (TR), a shift in content from some theme to the assigned topic (SIC), the amount of personal involvedness in the dream (PI), and a multiplicative combination of topic reference and shift in content scores (MC). Dream-like quality (DLQ) was a measure of the amount of imagery and bizarreness present in the report. 
A total of 16 dreams were controlled: 9 in the training group and 7 in the control group. The data revealed no differences between the two groups on NCM $[t(18)=.63, p<.40]$ and $\operatorname{PCM}[t(18)=.73, p<.25]$. The training group was found to be significantly higher on TR and $M C[t(18)=2.15, p<.025$ and $t(18)=2.31$, $\mathrm{p}<.025$, respectively], but no differences between the groups were found on $\operatorname{SIC}[t(18)=1.55, \mathrm{p}<.10]$ and $\mathrm{PI}[t(18)=.85, \mathrm{p}<.25]$. Comparisons on DLQ showed no differences between the training and control groups $[t(18)=1.47, p<.20]$ or between controllers and noncontrollers $[t(18)=1.49, \mathrm{p}<.20]$.

Topic pleasantness was found to have an effect on REM processes. A comparison of REM density (REMs per minute) between unpleasant and pleasant-topic controllers revealed the unpleasant-topic controllers had a significantly lower amount of REM activity $[t(11)=-1.84$, $p<.05]$. A comparison of the REMPs leading to controlled dreams showed the unpleasant-topic controllers were

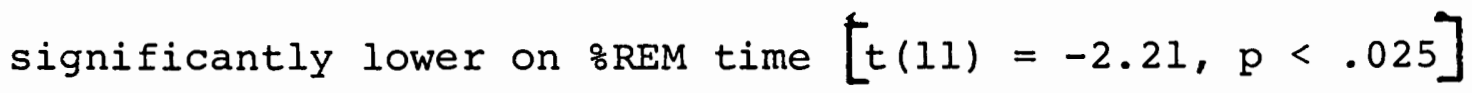
and REM density $[t(8)=-2.95, p<.01]$.

The training method was discussed and suggestions for improvement of the technique were made. The noted reductions in REM activity were evaluated in terms of presleep stress and anxiety. Methodological limitations of the study were also identified. It was concluded that 
the results of the study indicated further research was needed both on the cognitive-behavioral training method and the relationship between topic pleasantness and REM processes. 
A COGNITIVE-BEHAVIORAL APPROACH TO THE CONTROL OF DREAM CONTENT

by

GARY NICK DEAN LEHTO

A thesis submitted in partial fulfillment of the requirements for the degree of

\author{
MASTER OF SCIENCE \\ in \\ PSYCHOLOGY
}

Dortland State University

1980 
TO THE OFFICE OF GRADUATE STUDIES AND RESEARCH:

The members of the Committee approve the thesis

of Gary Nick Dean Lehto presented December 3, 1980

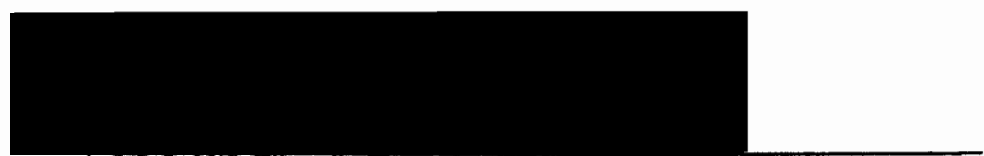

Gęrald Guthrie, Chairman

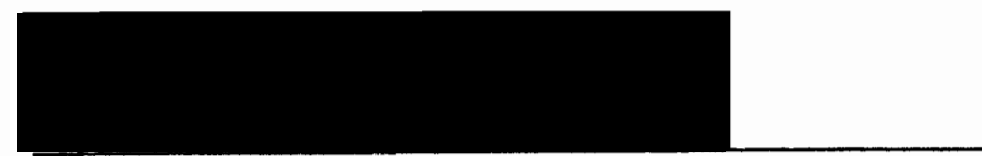

Milton K. Davis

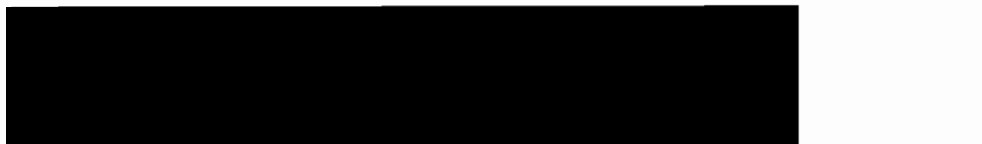

Barbara J.jstewart

APPROVED :

Robert E. Jones, Jr., Head, Department of Psychology

Stanley E. Rauch, Dean of Graduate Studies and Research 


\section{ACKNOWLEDGEMENTS}

There are a number of people whose invaluable interest and guidance made this research project possible. My chairman, Gerry Guthrie, really started the whole process with an idea which was to become the focus of this study. I thank Gerry for his warmth, time, and the probing questions which helped to form the foundation of this work. Very special appreciation is extended to Barbara Stewart, not only for her great statistical expertise and enormous amount of assistance on this project, but also for her thoughtful consideration and generosity toward me throughout my study at Portland State University. I thank Milton Davis for his support and suggestions on this project and for introducing me to another area of psychology. I am also grateful for the helpful comments of Barry Anderson and extend to him my thanks for his assistance in the early stages of this study. I sincerely believe I was fortunate to have the knowlegeable aid of each of these professors and will always regard them as very special people in my life.

A study of human behavior cannot be accomplished without the cooperation of those people who agree to serve as subjects. My subjects were willing to undergo great inconvenience, and because I did not know any of them 
before the study began, I regard their courage, trust in me, and willingness to reveal to me a very private and often intimate part of their life, as truly commendable. The running of this experiment demanded that I reverse my normal day-night schedule. I was pleased to discover I was not the only person awake each night here at Portland state. I thank all the friendly people of the night-maintenance staff for their cooperation and the consideration they gave to my sleeping subjects. A very special thank you is given to Lillian. Lillian shared the third floor of Cramer Hall with me and made my nights much less lonely with her interest, conversation, and numerous gestures of kindness. 


\section{DEDICATION}

Many long days and literally sleepless nights have been involved in the production of this thesis. No one better knows of and has shared the endless hours and trying times than my wife. In heartfelt appreciation of her patience, support, understanding, and encouragement, I dedicate this work to Janis. I could not have accomplished this without Janis, and I share with her the credit and pride. 
TABLE OF CONTENTS

PAGE

ACKNOWLEDGEMENTS. . . . . . . . . . . . . . . ii

DEDICATION. • . . . . . . . . . . . • . . . v v

LIST OF TABLES. . . . . . . . . . . . . . . . viii

LIST OF FIGURES . . . . . . . . . . . . . . . • ix

CHAPTER

I INTRODUCTION. • . . . . . . . . . . 1

II REVIEW OF THE DREAM LITERATURE. . • . • . . 3

III THE COGNITIVE-BEHAVIORAL MODEL
AND DREAM CONTROL . . . . . . . . . 13

IV PURPOSE OF THE STUDY. . . . . . . . . . 20

Statement of the Hypotheses . . . . . 21

V METHOD. . . . . . . . . . . 22

Subjects and Selection Measures . . . 22

Apparatus . . . . . . . . . . 24

Procedure ....... . . . . 25

VI RESULTS . . . . . . . . . . . 37

Content Measures. . . . . . . 37

Sleep Measures. . . . . . . . . 42

REM and REMP Reduction. . . . . . . 44

Postsleep Questionnaire and Interview . 47

Screening Measures. . . . . . . . 49 
VII

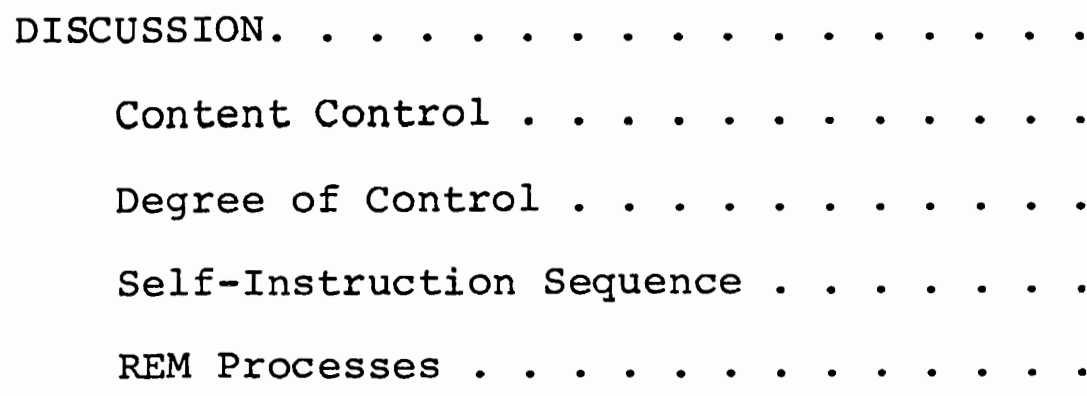

VIII FINAL REMARKS ............. 70

REFERENCES .

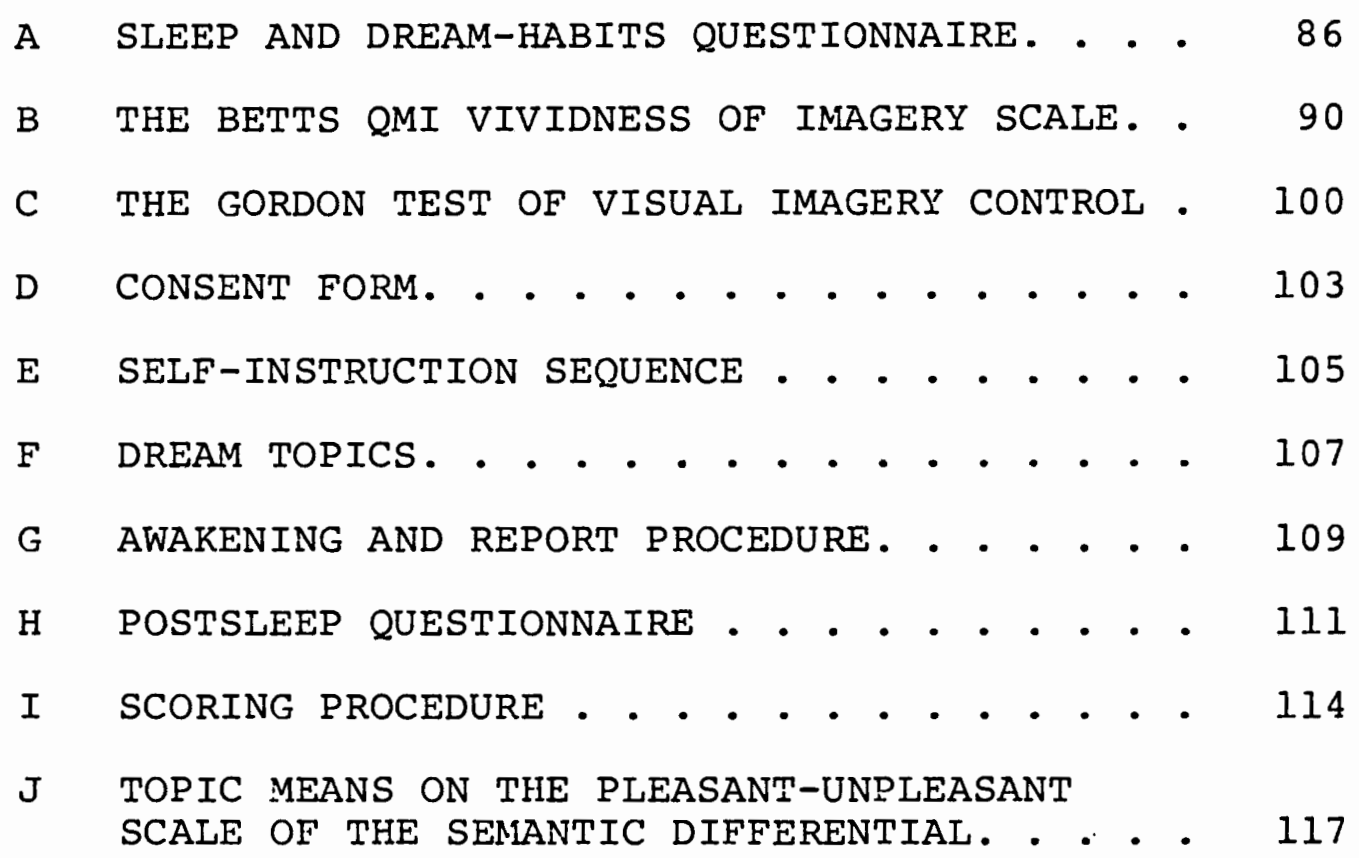




\section{LIST OF TABLES}

\section{TABLE}

PAGE

I Dependent Variables . . . . . . . 36

II REMP Awakenings Producing Controlled Dreams. . . . . . . . . . 38

III Interrater Reliabilities For Degree of

Control Variables........... 40

IV Correlation Matrix of Dependent Variables . . 41

$\mathrm{V}$ Screening Measures. . . . . . . . . 50 


\section{IIST OF FIGURES}

FIGURE

PAGE

1. The Cognitive-Behavioral Model. . . . . .

2. Dream Content Control in the CognitiveBehavioral Model. . . . . . . . . 
CHADTER I

INTRODUCTION

One mystery alone remains

of my beloved's sleep:

We've solved the movement of her eyes

And why they do repeat,

We know what brings her breath in sighs,

We've tracked her EEG;

The haunting doubt that still remains

Is does she dream of me?

Dr. Milton Miller

Approximately one-third of our lifetime is spent in sleep, and it is during this substantial portion of our existence that we experience the still very puzzling "inner" event of dreaming. Sleep has typically been regarded in Western cultures as a passive state with dreams considered as being relatively insignificant, beyond the realm of voluntary of conscious control, and distinctly different from waking thought. Although such traditional views are currently being challenged (Tart, 1965; Garfield, 1974) and there is evidence suggesting it is possible to control REM processes and dream content (Tart, 1965), research in the area of dreams has been neglected by behavioral researchers (Mahoney, 1974).

Recently, behavioral psychologists have begun to recognize the importance of cognitive processes in human behavior (Mahoney, 1974; Bandura, 1977; Meichenbaum, 1977). 
This movement is termed "cognitive behavior modification" and defined by Mahoney (1974) as being the conceptual and empirical analysis of private events (covert behavior). Although unexamined in the area of dreams, the inclusion of systematic training in the modification of covert (imaginal and verbal) behaviors in the waking state has been found to enhance treatment of various behavioral disorders (Mahoney, 1974; Meichenbaum, 1977). Due to the encouraging findings with various covert procedures in the waking state, it is interesting to consider whether dreaming is also a covert behavior which can be manipulated and developed in a similar fashion. If waking and sleep cognition are comparable and cognitive-behavioral training in the waking state can promote control over the inner event of dreaming, an extensive amount of behavior would become more directly accessible. The intent of the present study was to examine the effectiveness of a cognitive-behavioral technique in developing control over dream content. 
CHAPTER II

REVIEW OF THE DREAM LITERATURE

The objective study of such a private event as dreaming has indeed been very difficult. However, a major breakthrough in the scientific approach to dreaming was accomplished by Aserinsky and Kleitman (1953) with the discovery of the relationship between rapid eye movements (REMs) occurring during a low voltage brain wave pattern and dreaming. This and subsequent work (Aserinsky \& Kleitman, 1955; Dement \& Kleitman, 1957; Dement \& Wolpert, 1958) revealed that dreams were more likely to be reported when a subject was awakened during a REM period (REMP) than when REMs were absent (a non-rapid eye movement or NREM period). Furthermore, these early researchers provided a new methodology for the study of dreaming and enhanced the status of dreams as phenomena suitable for scientific inquiry by making the dream more accessible to both the dreamer and dream investigator.

Although the findings of Aserinsky and Kleitman (1953, 1955) suggested that dreams or any form of thought was generally absent during NREM stages of sleep, more recent evidence indicates that such is not the case. Foulkes (1962) found reportable mental activity in both 
REM and NREM periods of sleep with REM reports more closely resembling what is typically regarded as a dream (mentation containing more visual, emotional, physically active, and bizarre elements) than the NREM reports (more realityoriented, conceptual thoughts). In a review of the electrophysiological findings of sleep, Foulkes (1964) concluded that the available evidence indicated thought occurs continuely throughout sleep. Giora and Elam (1974) concurred with this position and argued that what psychologically differentiates states of sleep is not the existence or absence of mentation but rather its degree of adaptation to reality, with REM mentation showing lesser reality orientation than NREM thought. Although other research has shown that the distinction between REM and NREM mentation is not as clear-cut as this (Antrobus, Antrobus \& Fisher, 1965; Brown \& Cartwright, 1978), it is apparent that thinking does not cease during sleep.

Not only may thought be considered to occur throughout sleep, but contrary to the position of those considering dreaming to be qualitatively different from waking thought (Freud 1952, 1965; Cartwright, 1977), several researchers suggest that waking thought and dreams are similar and fall along a continuum of cognition. Foulkes and Fleisher (1975) found a higher than expected amount of dream-like cognition (regressive, hallucinatory-type thoughts) in the waking state of a group of normal subjects and also propose 
that waking and sleep cognition fall along a continuum. Starker (1973, 1977) has found structural and affective consistencies between daydreams and nightdreams and considers them to be highly interrelated aspects of fantasy processes in humans. Finally, McDonald, Shicht, Frazier, Shallenberger and Edwards (1975) provided evidence showing simple auditory stimuli can be processed and stored in short-term memory during all stages of sleep and information from long-term memory is accessible mostly during Stage 2 and REM sleep.

That sleep is not a behaviorally inactive period and sleeping and waking mentation are similar is further indicated by research showing behavior considered characteristic of the waking state is also found in sleep. Granda and Hammack (1961) found avoidance responses could be emitted during sleep without a return to the waking EEG. The use of other operant procedures has revealed that it is possible to make discriminations (Zung \& Wilson, 1961) and simple discriminative responses (pressing a hand microswitch) during sleep (Weinberg, 1966; Williams, Morlock \& Morlock, 1966; Salamy, 1971). Williams et al. (1966) suggested motor responding to simple external stimuli during REM sleep was especially difficult because external stimuli are blocked-out. However, utilizing a negative reinforcement procedure, these researchers showed responses to such stimuli during REMPs could be significantly increased with- 
out any distinct EEG signs of awakening. Of particular interest is the research showing it is possible to discriminate between REM and NREM mentation and to signal when dreaming is occurring by pressing a microswitch (Antrobus et al., 1965; Salamy, 1970; Brown \& Cartwright, 1978).

A number of investigators have used various methods to demonstrate the feasibility of direct manipulation of REM processes. Rechtschaffen and Verdone (1964) offered subjects money for increasing and decreasing dreaming time on particular nights. The amount of REM sleep was used to measure dreaming time, and a small but significant difference was found between the nights subjects were requested to increase their dreaming time and those nights they were requested to decrease dreaming time. However, due to the lack of a control condition (control group or baseline measure) in the study, it was impossible to determine whether subjects had actually increased or decreased their amount of REM sleep. A variety of techniques were employed by the subjects in their attempts to control dream time (ranging from repeating the incentive instructions to making no strong effort at all to control dreaming), but there was no consistent relationship between the attempted mode of control and the amount of time actually spent in REM sleep. Tart (1966) found post-hypnotic suggestion to be effective in promoting spontaneous self-awakenings at 
either the start or end of a REMP. Ogilvie, Busby, Costello and Broughton (1975) examined the effects of nonhypnotic suggestion on the REM sleep indices of dreaming using verbal instructions to either increase or decrease dreaming time. The percentage of REM time was found to be unaffected by experimental manipulations, but the number of REMs and REM density measures indicated increases which were in accordance with the suggestions given to the subjects. Also using non-hypnotic suggestion, Shollar (1975) found significant decreases in REMP length when subjects were instructed to end their REMPs after eight minutes (subject estimation). Operant conditioning techniques have also been shown to be effective in altering REM processes. Ellman, Shollar, Rosenbaum and Levine. (1968) and Ellman, Bowe and D'Aquini (1969) were able to decrease the amount of REM sleep occurring in the last three hours of sleep through the use of punishment (REM deprivation). Fiss and Ellman (1973) similarly found that subjects significantly shortened the length of their REMPs by terminating the REMP before a scheduled awakening time. Furthermore, the shortened REMPs occurred at the time of night when they typically become longer.

The notion that a sleeping individual may have direct control over dream content has been proffered by Stewart's (1972) observations of a culture practicing both presleep and concurrent control of dream content. This 
culture, the Temiar Senoi tribe of Malaysia, places a great deal of emphasis on dreams and begins educating its children in dreaming as soon as they can talk. The young children are told to control the events which occur in dreams and are offered encouragement for such a task through suggestions, directions, and social praise or criticism. Stewart (1954) indicates that from the dream collections he made from various age groups among the Senoi, the children do in fact gradually learn to control the content of their dreams. Stewart contends that like wakeful thinking, sleep thinking is highly amenable to suggestion and direction, and because cognitive preparation in the waking state carries over to the dream state, a continuity exists between day and night thinking. Stewart (1962) claims to have worked out a system of dream direction and reshaping modeled after the Senoi and found it to work well in the treatment of psychotic and psychosomatic patients. Although there is presently some question regarding the validity of Stewart's observations of the Senoi ("News \& Comment", 1978), the methods used by this culture have recently been attempted in group settings by Hart (1971) and Greenleaf (1973). In spite of the fact that neither author provided a quantitative analysis of the results, there were indications that content control had been achieved by some participants.

Laboratory research on content control has provided some limited support for the notion that dream content may 
be directly manipulated and further suggests that waking cognition and dreaming are similar and continuous forms of mental activity. Tart (1964), Stoyva (1965), and Tart and Dick (1970) found the use of posthypnotic suggestion to increase the probability of dreaming on a selected topic. However, the lack of comparison groups or baseline measures in each of these studies precludes a determination of the relative effectiveness of the hypnotic induction procedure. Tart and Dick (1970) also noted that during subsequent work with some of the same subjects, several reported to have learned to control the content of home dreams through self-administered instructions given prior to sleep onset. Thus, the investigators suggested the possibility that some individuals may possess the ability to control dream content without the use of hypnosis. Along these same lines, Barber, Walker and Hahn (1973) found hypnotic induction to be no more effective than non-induction in producing successful responses to dream about a suggested topic. Unfortunately, the cognitive activity engaged in by the subjects between the administration of the simple presleep instructions and the onset of sleep was not evaluated. Walker and Johnson (1974) concluded that hypnotic induction is not a necessary antecedent condition for a successful response to a presleep suggestion, and a simple instruction to dream about a particular topic may be just as effective as more involved procedures. 
Little research has been conducted in evaluating the effectiveness of nonhypnotic techniques in promoting content control. Garfield (1974) contends it is possible to preprogram dream content through waking autosuggestions and describes techniques for accomplishing this. Experimental investigations of these techniques by Foulkes and Griffin (1976) and Griffin and Foulkes (1977) failed to show any effect, but the researchers reliance on home recall and the apparently deficient monitoring of the subjects use of the techniques limits what may be said about the effectiveness of Garfield's (1974) methods. Finally, Ogilvie, Belicki and Nagy (1978) found that presleep instructions to either increase or decrease the amount of emotional involvement in sleep mentation were ineffective in promoting any affect changes in dream content.

It must be noted that a major limitation in all of the content control research has been the emphasis placed on the incorporation of stimulus material into the dream with little or no consideration given to the cognitive activity or method used by the subject in response to the presleep suggestion or instructions to dream on a particular topic. As Tart (1965) indicates it is no longer necessary to demonstrate that dream content can be manipulated or controlled and research should now be conducted to determine what techniques can best promote such changes, it would appear valuable to examine methods which take into account the cognitive activity of the subject. 
It has been suggested that dreams could be conceptualized as behaviors which may require direct modification (Cautela, 1968) and behavioral techniques might efficaciously provide control over dream content (Bergin, 1970). Case history reports on the use of systematic desensitization in the removal of nightmares have indicated that the procedure is effective in at least preventing an individual from dreaming particularly unpleasant or recurrent dreams (Geer \& Silverman, 1967; Silverman \& Geer, 1968; Bergin, 1970; Shorkey \& Himle, 1974; Cavior \& Deutsch, 1975); however, there has been no further reported research utilizing this or other behavioral methods in developing control capabilities to dream on selected topics. The current work emphasizing the role of cognition in behavior theory would appear to provide even greater potential for a behavioral approach to dream manipulation. This recent work also underscores the insistence that such research be undertaken. The findings of Maultsby and Gram (1974) exemplify both the potential of such an approach and the need for study in this area. While not explicitly attempting to promote dream content changes, these researchers reported that $32 \%$ of their patients had dream changes after underoing Rational Behavior Therapy which included the use of daily homework assignments and imaginal rehearsal ("rational emotive imagery"). of particular interest was the report of one patient having dreamed of emitting the 
same behavioral response which had been mentally rehearsed in the waking state. 
CHAPTER III

THE COGNITIVE-BEHAVIORAL MODEL AND DREAM CONTROL

The cognitive-behavioral model is a rather new and still tentative learning perspective. The most distinctive feature of this model is the importance attached to the role of mediation in human learning. Rather than conceptualizing human behavior only in terms of the external dimensions of stimulus-response chains, in the cognitivebehavioral learning model cognitive and symbolic processes are considered to be as important as external environmental events in influencing behavior. Thus, human behavior is seen as being understandable only when the interaction of both external and internal or self-generated events are taken into account.

Four integral factors or processes involved in complex human behavior have been discussed by Mahoney (1974); Craighead, Kazdin and Mahoney (1976); and Bandura (1977): attention, retention, component behaviors, and incentive conditions. Attention refers to an individual's selective awareness of internal or external events given the same environmental situation. Variability in responses of different individuals to the same environment may be 
partially accounted for by attentiveness to diverse stimuli. The factor of retention involves the cognitive representation of events which have been attended to. In order to promote lasting behavior change, it is important to ensure that material which has been attended to has also been recorded and made accessible for later use. The retention of learned material may be enhanced through verbal, imaginal, and motor rehearsal. Component behaviors reflect the necessity of a behavioral repertoire enabling an individual to emit a learned response. The attention and encoding of crucial environmental events will not result in the performance of a behavior unless the individual possesses the necessary behavioral skills. Lastly, incentive conditions refer to the consequences of behavior. Behaviors may be directed by not only externally administered consequences but also by self-generated, tangible or symbolic incentives. Figure 1 presents a simple illustration of these four processes and their relationship to incoming stimuli and outgoing responses. It should be noted that there is interaction between the processes, and although they have been treated here as being distinct and separate, the processes may overlap (Mahoney, 1974). Meichenbaum's $(1973,1977)$ impressive clinical work in self-instructional training indicates the importance of "inner speech" in mediating human behavior. This approach underscores the role of the above four processes 


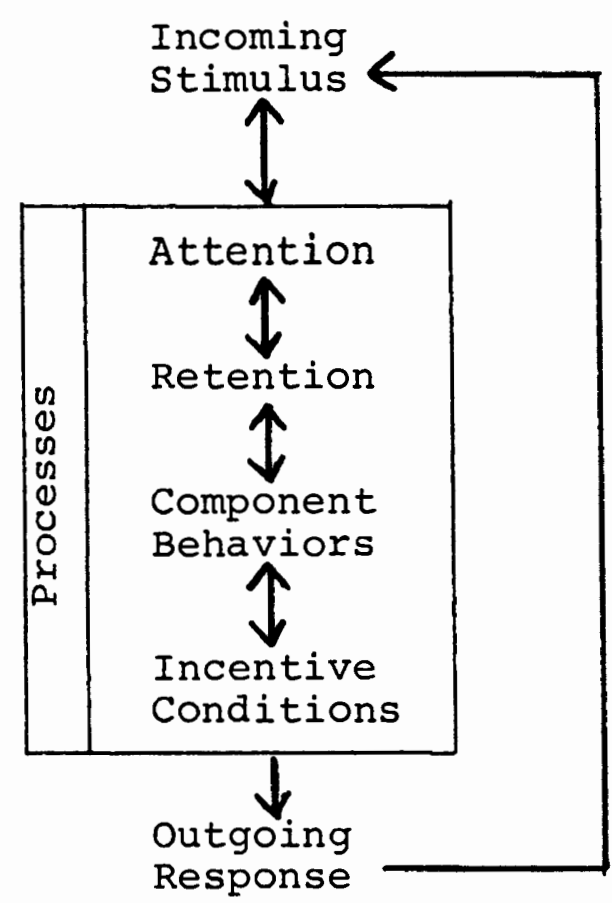

Figure 1. The cognitive-behavioral model.

in the cognitive-behavioral model with the proposition that a person's behavior is not determined by a stimulus situation per se but rather by the individual's thoughts about the situation. This internal dialogue or "self-talk" reflects the perception and evaluation of the stimulus and the perceived consequences of emitting a particular behavior. Thus, therapeutic intervention consists of training individuals to engage in self-instructions to monitor and control their own behavior. According to Meichenbaum (1977), self-instructional training promotes learning and change through: (1) increasing the distinctiveness of stimulus attributes, (2) focusing attention to the relevant dimensions of the task, and (3) maintaining information in short-term memory. The training is done in 
a gradated manner, moving from cognitive modeling by the therapist to covert verbalization by the client. The client is asked to rehearse the desired thought and behavior and to engage in self-evaluation.

Although the self-instructional procedure relies more heavily upon self-verbal mediation in changing particular thoughts and overt behavior, the strategy can be modified to also include the use of imagery. For example, Meichenbaum (1977) reported the use of a slow-moving turtle image to assist in controlling impulsive behavior in children. Rather than verbally monitoring performance, the children were asked to imagine a slow-moving turtle and to use this as a standard to guide their behavior. Also, Meichenbaum (1972) combined self-instructional training with a desensitization procedure which employed imagery and found this combination to be more effective in reducing test anxiety than either no treatment or desensitization alone.

Cautela (1970) has reported positive findings with a covert conditioning technique utilizing primarily imaginal mediation. In this procedure, called covert positive reinforcement, an individual is asked to imagine performing a target behavior and then to immediately imagine a reinforcing event. It is assumed that actual, overt performance of the target behavior is facilitated through the pairing of imagination of the response with an imaginal 
reinforcer. Mahoney (1974) notes that the evidence on the effectiveness of covert reinforcement is still quite modest. Although this is only speculation, it would appear that both self-instructional training and cove:st reinforcement rely on similar processes, and the effectiveness of covert reinforcement could be enhanced through the use of the self-instructional procedure.

The relationship between the cognitive-behavioral model and dreaming has not previously been addressed. However, because dreams are cognitive events relatively unaffected by external stimuli and more reflective of internal events (Dement \& Wolpert, 1958; Beck, 1969; Cartwright, 1969, 1977; Hobson \& McCarley, 1977), it would appear desirable to focus efforts toward dream control primarily on establishing this internal stimuli as a discriminative cue and developing a subsequent covert response of altering the dream content. Further indications of the potential for accomplishing this within the cognitive-behavioral perspective may be noted in terms of the four previously mentioned processes:

1. Attention. Cohen (1974) suggests that dream recall differences among individuals may in part be due to the varying levels of attention given to dream material both during sleep and in the waking state. It also appears that sleeping individuals are capable of distinguishing dreams from other forms of mentation (Antrobus et al., 
1965; Brown \& Cartwright, 1978). Thus, increased waking attention to the stimulus attributes of dreams should increase the likelihood of their recognition while asleep.

2. Retention. Maultsby and Gram (1974) attributed changes in aream content to the use of imaginal rehearsal as assigned homework. As mentioned earlier, McDonald et al. (1975) suggests simple information can be processed, stored, and remain accessible during sleep. Through rehearsal in the waking state, it is conceivable that information relevant to the recognition and manipulation of dreams could be retained for availability during sleep.

3. Component Behavior. Although there is no previous research suggesting what behavioral skills are necessary to actually manipulate dream content, the capabilities of imagery vividness and controllability might need to be fairly well developed in order to perform this response.

4. Incentive Conditions. Again related to dream recall, Cohen (1974) suggests the level of recall may be partially determined by the consequences for an individual in recalling a dream. If there is some importance attached to doing so, either external encouragement or self-generated incentives, more of this material might be recalled. Regarding content manipulation, Stewart (1972) noted that the Senoi children received social praise and encouragement 
in their attempts to manipulate dream content, and it was found that content control capabilities did develop. Thus, the use of contingent reinforcement would seem to be an important dimension in developing content control.

Figure 2 offers an illustration of the above aspects of content control in relationship to the cognitivebehavioral model. It should be noted in this diagram that both the incoming stimulus and outgoing response are covert or private events.

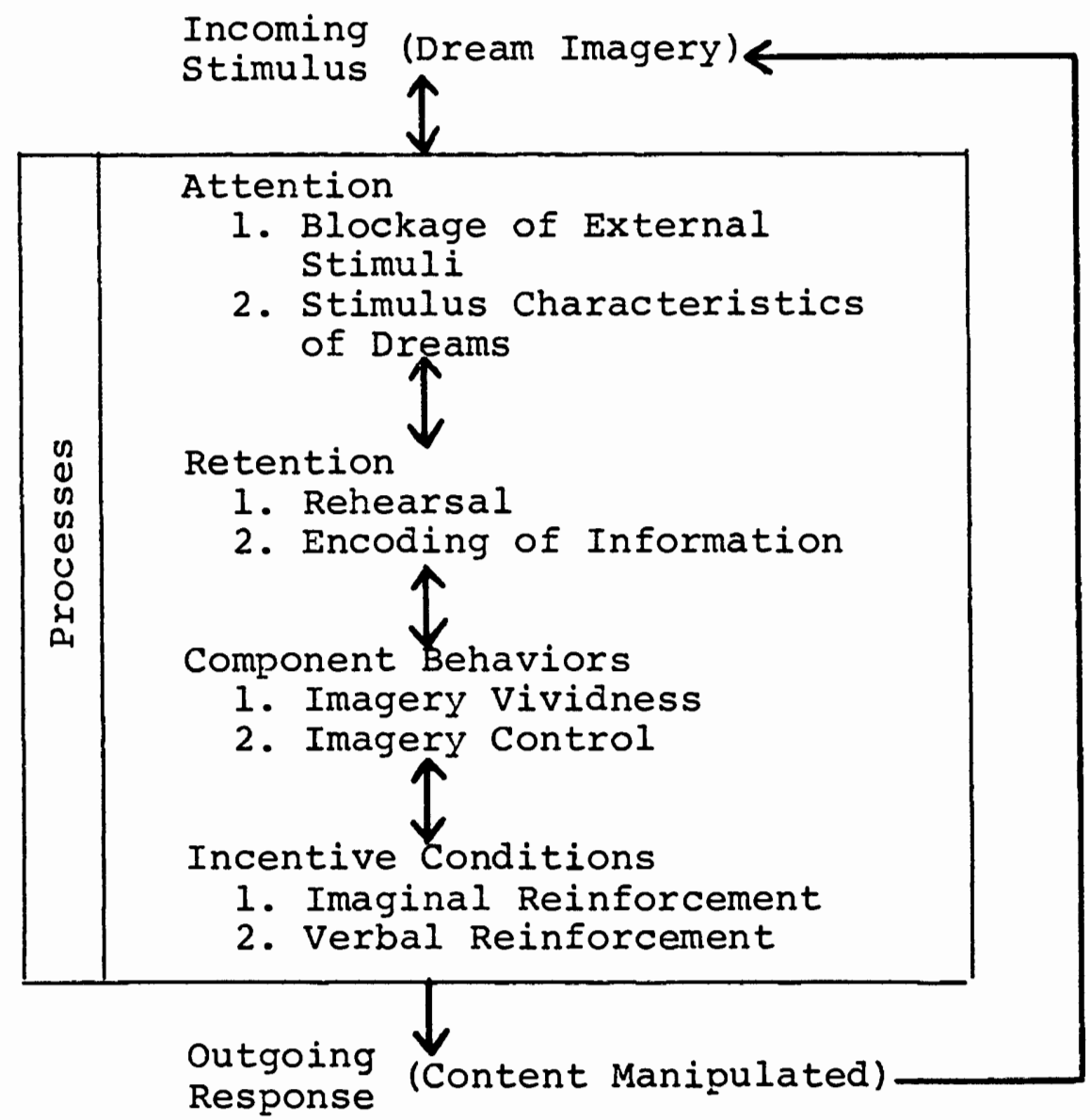

Figure 2. Dream content control in the cognitive-behavioral model. 
CHAPTER IV

PURPOSE OF THE STUDY

The preceding literature review showed there to be evidence indicating similarity and continuity between sleep mentation and the mental activity of waking life, and although there is obviously disparity between the waking and sleep states (e.g., in physiological processes), the differences noted in mental activity may only be quantitative in nature. It was also seen that previous research has found individuals to be capable of altering dream content and REM processes through various waking instructions and methods. However, it is clear that much of the work in these areas is still preliminary, and specifically in the area of content control, the effectiveness of various procedures needs to be examined.

The purpose of this exploratory study was to examine the extent to which cognitive-behavioral training in the waking state would increase the probability of dreaming on a selected topic, as indicated by verbal reports obtained from subjects awakened from REM sleep. The effectiveness of this training was evaluated by comparing the training group with an attention-placebo control group which received no actual instruction in content manipulation. 
Statement of the Hypotheses

The primary focus of this study was on content control, and it was hypothesized that subjects receiving cognitive-behavioral training would exhibit a significantly greater amount of controllea dreams than would the subjects not receiving this training. It was also anticipated that the degree of control found in the reported dreams would vary between the two groups. Thus, as a secondary focus of the study, it was predicted that the degree of control found in the dreams of the cognitive-behavioral group would be greater than that found in the dreams of the attention-placebo control group.

A final area of concern was the quality or "dreaminess" of the reported dreams. No predictions were made for this dimension, and it was included primarily to detect any qualitative differences between controlled and uncontrolled dreams. 
CHAPTER V

METHOD

Subjects and Selection Measures

Twenty paid subjects, 12 females and 8 males, ages 18 to 52 , were selected from the undergraduate population of Portland State University on the basis of their responses on three questionnaires (see Appendices $A-C$ ): a sleep and dream-habits questionnaire devised by the experimenter; the Betts QMI Vividness of Imagery Scale (shortened form), as it appears in Richardson (1969); and the Gordon Test of Visual Imagery Control, also as it appears in Richardson (1969).

The Betts QMI is a subjective measure on which subjects were asked to rate the clarity and vividness of various images in different sensory modalities. A rating scale of 1-7 points is used for each image, with ratings of 1 point indicating images "perfectly clear and as vivid as the actual experience," and ratings of 7 points representing "no image at all, you only 'knowing' that you are thinking of the object." Both the visual scale and the total test scores of the subjects were examined. The questionnaire is constructed so that total scores on the visual scale can range from 5-35 points and from 35-245 
points on the complete test. In both cases the lower scores indicate a greater amount of imagery vividness and clarity. The test has been shown to have a testretest reliability of .91 (Evans and Kamenoto, 1973) and from .95-.99 on internal reliability (Juhasz, 1972).

The Gordon test is a simple subjective measure on which subjects are asked to visualize an automobile in different colors, positions, and settings. Subjects respond to each of the 12 items of the test with a "yes," "no," or "unsure" rating depending on their ability to visualize the described scene. The emphasis of this test is on controlling or manipulating the images and not on the clarity of the imagery. Only "yes" and "no" responses were used in this study; thus, the scores on this test could range from 0-12 points with the higher scores indicating greater visual imagery control. Juhasz (1972) found the odd-even reliability of this measure to vary from .88-.95, and McKelvie and Gingras (1974) found a test-retest reliability of .84 .

A measure of home recall was taken using a question from a questionnaire employed by Hiscock and Cohen (1973) and which had earlier been found to be a valid predictor of sleep-interruption recall. Subjects are asked on this question to rate the frequency of home recalled dreams for the previous two weeks. These ratings can vary from 0 points, indicating "not sure", to 7 points, representing 
"every morning". This question was used in the sleepand dream-habits quesionnaire, along with questions concerning sleep and waking times, interest in dreams and this research project, previous control, and belief in the possibility of controlling dream content.

As a relationship appears to exist between the visual imagery of dreaming and wakefulness (Hiscock and Cohen, 1973; Starker, 1973, 1977) and because waking imagery was to be utilized in this study, subjects chosen to participate were those who scored in the higher ranges of imagery vividness and visual imagery control. Attempts were also made to acquire subjects who reported to be high recallers and good sleepers, had either previously controlled the content of a home dream or at least expressed a belief in the feasibility of such a behavior, had a regular bedtime, were not under any medication, and for whom the laboratory arrangement approximated home-sleep schedules and routines.

\section{Apparatus}

The sleep laboratory consisted of two adjacent rooms locate $\vec{a}$ on the third floor of Cramer Hall at Portland State University: a sleeping room and a monitoring room. The sleeping room contained a rollaway bed, a large table on which a microphone was placed, a ceiling speaker, a buzzer to awaken the subject, and a cassette recorder to tape the dream reports. Self-adhering surface electrodes were used to monitor the electrooculogram (EOG) and $9 \mathrm{~mm}$ 
silver disc electrodes were used for the electroencephalogram (EEG). Electrodes from the subject were connected to shielded extension cables which in turn led into a wall plugboard. Above the plugboard was a large one-way window, the other side of which was located in the monitoring room. This window was covered by curtains in both rooms in order to block out any light from the monitoring room and to instill a sense of privacy in the subject. Below the one-way window in the monitoring room, there was a corresponding wallplate from which the cables led into a four-channel physiograph (Narco-Biosystems, Model 4-A). The controls for the cassette recorder and buzzer were in the monitoring room and communication with the subject was via the sound system.

\section{Procedure}

The 20 subjects were randomly assigned to the following two conditions: (1) an attention-placebo control group and (2) a cognitive-behavioral training group. Each group was composed of six females and four males. Subjects from the assigned groups met in smaller groups of two or three individuals for three hours of classroom instruction. These smaller groups met once a week for two weeks and each session was of $1 \frac{1}{2}$ hours in duration. At the beginning of the first session subjects were again given a description of the study outlining the laboratory procedure to be used and the responsibilities and expectations of the subject 
while involved with the experiment. The subjects were allowed to view both rooms of the sleep laboratory and were given an opportunity to express any concerns regarding the procedure or the sleep environment. Subjects were then asked to sign a consent form (see Appendix D).

Each group was told that the focus of the study was on the control of dream content and the purpose of the two meetings was to provide a form of training designed to enhance and develop content control capability. The remainder of the format used in each group was different and is briefly described below:

Group I: Attention-Placebo Control Group. The purpose of this group was to control for the effects of content manipulation due to increased attention given to dreaming along with the expectation of receiving training in controlling the content of dreams. The first session for this group consisted of a presentation on dreams and dreaming. Emphasis was placed on research findings providing positive results in the manipulation of dream content and REM processes. This was done to instill an expectation of being able to successfully control dream content when sleeping in the laboratory; however, no information or suggestions were given regarding the methods used to control content or processes. The second session was a discussion period focusing on the subjects' views of dreams, the emphasis and value the subjects 
placed on them, and the relationship between dreams and waking behavior. From the time the subjects entered training until the second night of laboratory sleep, each was asked to record all recalled home dreams.

Group II: Cognitive-Behavioral Training Group. The training group received an actual technique to practice and use in attempting to control dream content. During the first meeting a brief presentation of dreams and dreaming was made emphasizing the distinction between the more perceptual-type thought commonly occurring during REM sleep and the conceptual thinking typically found in NREM sleep. This group was then introduced to a self-instruction sequence (see Appendix E) to use in attempting to dream on a selected topic. The sequence was presented in cognitive-behavioral terms with dreaming considered to be a covert behavior which could serve as a discriminative stimulus to cue a covert response of directing further dreaming. Further, performance of the imaginal response (i.e., directing dream content) was to be facilitated through the use of covert reinforcement. Cognitive modeling was used to demonstrate and delineate the series of covert events involved in the self-instruction sequence. The initial portion of the second session was spent reviewing the subjects use of the sequence, with special attention given to the cuing imagery and covert reinforcement. Subjects were then introduced to a progressive relaxation exercise, 
and the remainder of the meeting was spent practicing the sequence and discussing any problems with its usage. Daily homework assignments were given with instructions to practice and record the use of the sequence. Subjects were also requested to attempt to dream about a topic of their choosing at home and to record the topic selected along with any recalled dreams.

After completion of the training phase of the experiment, every subject individually spent two consecutive nights in the sleep laboratory. Before each night of sleep, electrodes were attached to the subject to monitor sleep. The first night of sleep was an adaptation night of uninterrupted sleep and recordings were made only during approximately the first and last hours of sleep. This night provided a period of adjustment to the foreign sleep environment and electrode attachments, and allowed the experimenter to note any electrode placement or equipment problems. The second night of sleep constituted the posttest portion of this experiment. After the same electrodes were again attached, subjects in each of the two groups were read a set of instructions and assigned a topic to dream about throughout the night. Each topic was randomly assigned from a list of five semantically different topics (see Appendix F): (1) Climbing Trees, (2) Being Locked in Jail, (3) Finding Money, (4) Floating in Water, and (5) Fighting in a War. As each 
subject was assigned only one topic and there were ten subjects in each group, every topic was assigned to two people in both the control and training groups. Subjects had no knowledge of the other four unassigned topics. The instructions read to the subject were the following:

Tonight I am going to awaken you to find out what you were dreaming or thinking about while you were asleep. I want you to really concentrate on your areams tonight and during every dream I want you to dream about (assigned topic, e.g., Climbing Trees), so, your topic is (Climbing Trees). I'd like you to put this into the form of an autosuggestion, "Tonight I will (be climbing trees)"; so, your suggestion is, "Tonight I will (be climbing trees)". Now, repeat back your suggestion to me. (Subject repeated back suggestion and it was clarified if there were problems.) Good. Remembering the material we covered in our training session, try to dream on this topic.

During certain periods of the night I will awaken you and ask you to report whatever was going through your mind. What I will do is sound the buzzer, call your name, and ask you, "What was going through your mind just before you were awakened?" I would like you to report whatever thoughts you were having as honestly and accurately as possible. Because I do not want to disrupt your recall, I will not be talking with you other than to ask you a couple of short questions, such as, "Is there anything else?" Try to recall everything you can about your dreams or thoughts. To show you what the procedure will be like, we will make a practice run. (The experimenter left the sleep room. Two minutes later the buzzer was sounded, the subject's name called until some form of verbal response was given and then the subject was asked, "What was going through your mind just before you were awakened?") Good. Thank you (subject's name). (The experimenter reentered the sleep room.)

To make sure that you understand what I want you to do tonight, please repeat back to me your suggestion. (Subject repeated suggestion and it was clarified if needed.) Right. When I awaken you, remember to try to describe all the thoughts you were having prior to the awakening. For 
example, if you awaken and have been dreaming of the topic, instead of just saying, "I was dreaming of (Climbing Trees)", try to tell everything you can remember about the dream. Even if your dream is of something other than the topic, again try to give a detailed description of the dream or thoughts: who, what, when, where, what kinds of things or events were occurring, what you were doing and feeling, etc. In other words, everything that comes to your mind is good material for you to report. After I have asked the question, "What was going through your mind just before you were awakened?", if it is helpful for you to reflect on the dream for a moment before beginning the report, go ahead and do so. I will be recording your reports so try to speak loudly and clearly. Are you comfortable? Do you have any questions? Good night.

After the instructions were given, the experimenter turned out the lights, left the sleeping room, and the subject was allowed to go to sleep. The lights were not turned on and the experimenter did not reenter the sleeping room until the subject had been awakened for the final time, unless equipment difficulties were encountered or the subject requested assistance from the experimenter.

Physiological recordings consisted of bipolar frontal EEG-left ear $\left(A_{1}\right)$ placements and one channel of EOG, right versus left eye. The scoring system of Rechtschaffen and Kales (1968) was used to assist in determining sleep onset and REM sleep. However, as the recommended electromyogram (EMG) recording could not be made due to equipment limitations, precise measurements of sleep onset and stages could not be obtained. Approximations were made by defining sleep onset as the appearance of the first sleep 
spindle and REMP onset as the appearance of the first REM occurring during relatively low voltage, mixed frequency EEG activity. The limitations of this procedure are discussed later.

During each REMP of the second night of sleep, subjects were awakened to obtain a dream report. Thus, dreams were operationaliy defined as the mental activity reported from awakenings interrupting REM sleep. Attempts were made to stay with a standardized awakening and report procedure (see Appendix G), but due to equipment problems and other difficulties (e.g., the subject speaking too softly), this procedure could also only be approximated. The awakenings were made according to a modification of the timetable used by Brown and Cartwright (1978):

1. First awakening - 5 minutes after REMP onset or immediately after a stage change following a large body movement.

2. Second awakening - 10 minutes after REMP onset or immediately after a stage change lasting longer than 1 minute, following a large body movement.

3. Third awakening - 15 minutes after REMP onset or immediately after a stage change lasting longer than 2 minutes, following a large body movement.

4. Fourth and subsequent awakenings - 20 minutes after REMP onset or immediately after a stage 
change lasting longer than 2 minutes, following a large body movement.

On the morning following the posttest night, subjects completed a short questionnaire (see Appendix $\mathrm{H}$ ) and were asked by the experimenter to reconstruct what they had done in their attempts to dream on the assigned topic. Finally, each subject's participation was terminated with a detailed explanation of the experiment and payment of $\$ 10.00$ for their assistance.

The dream reports which had been tape recorded were then transcribed. Care was taken to delete both information revealing the identity of the subject and references to the dream topic not reported as occurring in the dream. As a check on the accuracy and uniformity of the REM sampling procedure, the physiological tracings were reviewed by the experimenter and a report was excluded if it had resulted from: (1) an awakening following an immediate return to REM sleep after a report had been given and the subject was instructed to go back to sleep (back-to-REM awakening), and (2) any identified REMP which was composed of more than 50\% NREM sleep or less than $50 \%$ of the needed time for that awakening. This resulted in 81 usable reports.

The dream reports were given to two independent judges who were trained in the scoring procedure (see Appendix I). These judges were familiar with the experiment 
but were "blind" as to which group any report belonged and which topic had been assigned to elicit that report. The reports were given to the judges in a random, reversed order so that each judge read the reports in the exact opposite order from the other.

The judges were asked to individually read each report, identify which topic had been assigned to the subject to obtain that particular report, and give a reason for making their report-topic match. The matches made by each judge were then coded by assigning 0 points for an incorrect match and 1 point for a correct report-topic match. Although the judges had been encouraged to guess when none of the topics appeared to fit the report, these guess answers were considered as a "none of the above" response and were coded as an incorrect match. As dreams were simply defined as reports obtained from REM awakenings, no other distinctions were made as to the length or detail of the report needed to qualify as a dream. Also, no distinctions were made between contentless or dreamless reports, and any no-recall reports were counted as an incorrect match. (This actually was a reasonable procedure because reports of no recall were not so far removed from some of the reports obtained from both groups.) The matches of the two judges were compared and a correct report-topic match was said to have been made only when both judges correctly matched the report with the 
assigned topic. The matching results were then used to analyze content control which was operationally defined as: (1) the number of correct report-topic matches (NCM) and (2) the proportion of correct report-topic matches (PCM) .

The judges also scored each dream report on three degree of control measures: (1) the number of direct and/or indirect topic references in the dream (TR), (2) the noted absence or presence of a shift in content from some topic to the assigned topic (SIC), and (3) the extent of personal involvedness in the dream (PI). Scores on TR could range from $0-4$ points, with the score of 0 indicating no references to the topic and 4 points indicating a direct reference to both the verb and object of the topic. The SIC score was simply the assignment of 1 point if this shift was lacking and 2 points if there was a shift to the assigned topic. The range of PI scores was $0-2$ points, with 0 meaning the subject was a passive observer of the dream and 2 points indicating the subject was personally involved in the topic action. A fourth degree of control variable, multiplicative combination (MC), was a score calculated by multiplying the TR score by the score on SIC. This measure was computed by the experimenter, and values could range from 0-8 points. One score on each of the degree of control measures was obtained for every report by averaging the scores of the 
two judges. However, all of these measures were automatically regarded as incorrect and given a score of 0 points if a correct report-topic match had not been made by both judges. One final value was obtained for each subject on all of these variables by computing the average degree of control per controlled dream.

Finally, the judges rated each report on a slightly modified version of Brown and Cartwright's (1978) measure of dream-like quality (DLQ). This rating could be given regardless of whether or not the report had been correctly matched. Scores could vary from 0 points, indicating no recall, to 4 points, meaning the dream had two or more images, a connecting story, and some bizarreness. Here again one value was obtained for each report by averaging the scores of the two judges, and one final score was found for each subject by calculating the average DLQ per report.

Table 1 summarizes the seven dependent variables which were of interest in this experiment. It will be noted there were two variables used to define content control, four defined degree of control, and the final variable was that employed to measure the quality of the reported dreams. 
TABLE I

\section{DEPENDENT VARIABLES}

I. Primary Focus: Content Control

A. Number of correct dream report and topic matches (NCM). (Number of controlled dreams.)

B. Proportion of correct dream report and topic matches (PCM). (Proportion of controllea dreams.)

II. Secondary Focus: Degree of Control

A. Number of direct and/or indirect references to the assigned topic (TR).

B. Absence or presence of a shift in content to the assigned topic (SIC).

C. Amount of personal involvedness in the dream (PI).

D. Multiplicative combination of topic references and shift in content scores (MC).

III. Quality of Dreams

A. Scores on the modified Brown and Cartwright (1978) rating scale of Gream-like quality (DLQ). 
CHAPTER VI

RESULTS

\section{Content Measures}

Dream recall for the two groups was high: only 3 out of 42 awakenings (7\%) in the control group resulted in no recall and some information was obtained from each of the 39 awakenings in the training group. As indicated earlier, content analyses were done using these 81 awakenings (reports).

The two judges were in agreement on a total of 16 correct report-topic matches (20\% of the reports): five subjects in the control group manipulated a total of 7 dreams (17\% of the control group dreams) and eight subjects in the training group controlled 9 dreams (23\% of the training group dreams). As may be seen in Table II, these 16 controlled dreams did not result from any particular REMP awakening. It is also noteworthy that 27 (33\%) of the reports, 11 (26\%) from the control group and 16 (41\%) from the experimental group, were matched with topics which had not been assigned; that is, both judges agreed on 27 incorrect report-topic matches. Interrater reliability for the correct report-topic matches was computed using the phi coefficient and was found to be acceptable $(\phi=.78, \mathrm{~N}=81)$. 
TABLE II

REMP AWAKENINGS PRODUCING CONTROLLED DREAMS

REMP

Number of Controlled Dreams

Group I: Attention- Group II: CognitivePlacebo Control Behavioral Training

Total

1

1

2

3

2

2

2

4

3

2

3

5

4

2

$I$

3

5

0

0

0

6

0

I

1

1. Primary Focus: Content Control. The prediction of the primary focus of this study was not supported by either of the two content control variables. Although the differences between the two groups were in the predicted direction on both NCM and PCM, these differences were very small $[t(18)=.63, p<.40$ and $t(18)=.73, p<.25$, respectively]. The slight differences between the groups become even more apparent if the number of subjects needed in each group to reach significance is computed using the means and standard deviations found with the sample size used in this study $(N=10)$. For NCM, the difference between the training group $(M=.90, S D=.57)$ and the control group $(M=.70, S D=.82)$ would only reach 
significance with an $N$ of $69[t(136)=1.66, p<.05]$. For the variable of PCM, the training group $(M=.25, S D=$ .19) and control group $(M=.18, S D=.23)$ difference would reach significance with an $\mathrm{N}$ of $53[t(104)=1.68$, $p<.05]$. Furthermore, using the $t$ values obtained for these calculated sample sizes, the strength of the significant relationship could be estimated using $\omega^{2}$ (Hays, 1973). This relationship would also be very small for both $\operatorname{NCM}\left(\omega^{2}=.013\right)$ and PCM $\left(\omega^{2}=.017\right)$. Thus, the training procedure produced little effect on content control, and the amount of variance accounted for in NCM and PCM by the training was negligible.

2. Secondary Focus: Degree of Control. The Pearson $r$ was used to calculate two sets of interrater reliabilities for each of the degree of control variables (see Table III). The first column of Table III shows the reliabilities using information obtained from all of the 81 dream reports. Again, this was the number of reports used in the final analyses of the degree of control variables, and the reliabilities indicated that, with the exception of PI, the two judges were in very high agreement. However, these reliabilities were overinflated due to the fact that every degree of control measure needed to be scored as being incorrect (assigned 0 points) if a correct report-topic match had not been made. This procedure extended the range of values for SIC scores from 1-2 points to 0-2 points, and 
a score of 0 points assumed a dual meaning on all of the other degree of control variables: either the variable was incorrect or there was a lack of control on that particular measure. For these reasons a second, comparison set of reliabilities was computed using 43 reports. This second set of reliabilities reflected the extent to which the judges were in agreement on the degree of control measures when they had agreed on the report-topic match, regardless of whether or not the report was correctly matched with the assigned topic. Here it may be noted that the reliabilities for $T R$ and $M C$ were still high but were substantially lowered for SIC and PI. The extremely poor reliability for PI would suggest that further analysis of this variable would, at best, be imprecise.

\section{TABLE III}

INTERRATER RELIABILITIES FOR DEGREE OF CONTROL VARIABLES

\begin{tabular}{|c|c|c|}
\hline \multirow[b]{2}{*}{ Variable } & \multicolumn{2}{|c|}{$\begin{array}{l}\text { Sample Size (Number of } \\
\text { Reports): }\end{array}$} \\
\hline & $N=81$ & $N=43$ \\
\hline Topic References (TR) & .98 & .92 \\
\hline $\begin{array}{l}\text { Shift in } \\
\text { Content (SIC) }\end{array}$ & .81 & .50 \\
\hline $\begin{array}{l}\text { Multiplicative } \\
\text { Combination (MC) }\end{array}$ & .95 & .82 \\
\hline $\begin{array}{l}\text { Personal } \\
\text { Involvedness (PI) }\end{array}$ & .71 & .18 \\
\hline
\end{tabular}


Two of the degree of control variables supported the prediction of the secondary focus of the study. The training group was significantly higher on TR $[t(18)=$ $2.15, \mathrm{p}<.025]$ and $\mathrm{MC}[t(18)=2.31, \mathrm{p}<.025]$. Using $\omega^{2}$ to estimate the strength of the relationship between the training method and each of these measures indicated that training accounted for $15 \%$ of the variance in TR and $18 \%$ of the variance in MC. Although in the predicted direction, there were nonsignificant differences between the two groups on $\operatorname{SIC}[t(18)=1.55, \mathrm{p}<.10]$ and PI $[t(18)=.85, p<.25]$. The training method was estimated to account for $7 \%$ of the variance in SIC, but due to the questionable interrater reliability on this variable, this estimate should be viewed with caution. It is also noteworthy that MC was highly intercorrelated with TR but not with SIC (see Table IV). For this reason the significant difference between the two groups on MC is considered to reflect a higher contribution of the TR scores.

\section{TABLE IV}

CORRELATION MATRIX OF DEPENDENT VARIABLES

\begin{tabular}{|lllllllll|}
\hline & & 1 & 2 & 3 & 4 & 5 & 6 & 7 \\
\hline 1. & $\mathrm{NCM}$ & - & & & & & & \\
2. & $\mathrm{PCM}$ & $.88^{* *}$ & - & & & & & \\
3. & $\mathrm{TR}$ & -.40 & -.19 & - & & & & \\
4. & $\mathrm{SIC}$ & .40 & $.48 *$ & -.32 & - & & & \\
5. & $\mathrm{MC}$ & -.13 & .11 & $.88 * *$ & .09 & - & & \\
6. & $\mathrm{PI}$ & .04 & .03 & .28 & -.24 & .16 & - & \\
7. & $\mathrm{DLQ}$ & .05 & .03 & .24 & .39 & .37 & .22 & - \\
$\mathrm{N}=$ & $20,{ }^{*} \mathrm{P}<.05,{ }^{* *} \mathrm{P}<$ & .01 & & & &
\end{tabular}


3. Dream-Like Quality. Interrater reliability was high on the measure of $\mathrm{DLQ}(r=.86, \mathrm{~N}=81)$ and comparable to that reported by Brown and Cartwright (1978). Because nó predictions were made for this variable, two-tailed $t$ tests were used in making comparisons.

Although the training group was higher on DLQ for all reported dreams, this difference was nonsignificant $[t(18)=1.47, p<.20]$, and a comparison of the two groups for only controlled dreams revealed the training group was once again only slightly higher $[t(18)=1.24$, $\mathrm{p}<.30]$. A final comparison between subjects controlling dreams and those not controlling any dreams showed the controllers were not significantly higher on this measure $[t(18)=1.49, \mathrm{p}<.20]$.

To summarize, although the content analyses revealed there were no differences in the number or proportion of dreams actually controlled, there was some limited support for the prediction that the dreams of the training group would more closely resemble the assigned topics. The results also indicated the "dreaminess" of the reports were similar for both groups, and the controlled dreams were at least as dream-like as the uncontrolled dreams.

\section{Sleep Measures}

Two-tailed $t$ tests of the continuous sleep recordings from the posttest night showed subjects in the control 
group had a significantly greater amount of sleep than did those in the training group $[t(18)=2.43, p<.05]$ and spent slightly more time in REM sleep $[t(18)=1.88$, $p<.10]$. However, since there was no difference in the percentage of REM sleep ( 8 REM time) for each group $[t(18)=1.17, p<.30]$, it is therefore considered that the posttest night of sleep was comparable for each group, and although the control group had an opportunity to experience more REM time and could provide slightly more reports, the differences in total sleep and REM time are not believed to be a major factor affecting the content and degree of control analyses. No differences were found on either the initial sleep onset latency $[t(18)=.22$, $p>.80]$ or the time it took subjects to return to sleep after providing a dream report $[t(18)=-1.47, \mathrm{p}<.20]$. Thus, on at least an objective measurement of the time subjects could possibly have spent thinking about the assigned dream topic, there were no differences in the quantity of waking time.

Comparisons between subjects controlling dreams and those failing to control any dreams revealed no differences in total sleep time $[t(18)=-.37, p<.80]$, total REM time $[t(18)=-.64, p<.80]$, and 8 REM time $[t(18)=-.41$, $\mathrm{p}<.80]$. There was no difference in the initial sleep onset latency $[t(18)=-.98, p<.40]$, and although those not controlling any dreams took slightly longer to fall 
back to sleep after reporting a dream, this difference was also not significant $[t(18)=-1.36, p<.20]$. Again, these latter two objective measurements indicated that those successfully manipulating dreams did not spend any more time staying awake in attempting to exert this control.

REM and REMP Reductions

Although the focus of this study was on dream content rather than processes, early in the study it was noted that subjects assigned topics which had previously been rated as being unpleasant (see Appendix J: Being Locked in Jail and Fighting in a War) appeared to be having less REM time and fewer REMs than those assigned topics viewed as being more pleasant (see also Appendix J: Climbing Trees, Finding Money, and Floating in Water). On the basis of this early observation, it was predicted that subjects assigned unpleasant topics would have less REM time and a lower REM density than those assigned pleasant topics. The measure of $\frac{\mathrm{R}}{\mathrm{R}} \mathrm{M}$ time was chosen to compare amounts of REM sleep, and the number of REMs per minute (REMs/min) was used as a measurement of REM density.

First of all, as reference points, two-tailed $t$ tests revealed there were no significant differences between the control and training groups on REMs/min $[t(18)=-.86, p<.50]$ and, as presented earlier, \&REM time $[t(18)=1.17, p<.30]$. There were also no significant 
differences between subjects controlling areams and those not controlling any dreams on both REM density $[t(18)=$ $-1.01, p<.40]$ and, as again already mentioned, \&REM time $[t(18)=-.41, p<.80]$.

Six subjects were assigned pleasant topics in each the control and training groups, and four individuals in each group were assigned unpleasant topics. Of the assignments made, three subjects in the control group and five in the training group controlled at least one pleasant-topic dream while at least one unpleasant-topic dream was controlled by two control group and three training group subjects. Comparisons of all subjects by assignment only (i.e., irrespective of success in controlling any dreams) revealed that, contrary to the direction predicted, subjects assigned unpleasant topics had a nonsignificantly higher $8 \mathrm{REM}$ time $[t(18)=.30, \mathrm{p}<.40]$; however, a difference in the predicted direction approached significance on REMs/min $[t(18)=-1.64, p<.10]$. A nonsignificant difference in the predicted direction was found for $8 R E M$ time between the five subjects actually dreaming on the assigned unpleasant topics as opposed to the eight subjects dreaming on the assigned pleasant topics $[t(11)=-.29, p<.40]$, and those dreaming on the unpleasant topics had significantly fewer REMs/min $[t(11)=-1.84, p<.05]$. When the REMPs from which controlled dreams had been reported were compared, \&REM 
time (in this case, Controlled REMP Time/Total sleep

Time) was significantly lower for subjects controlling unpleasant dreams $[t(11)=-2.21, p<.025]$, and these same subjects had significantly fewer REMs/min $[t(8)=-2.95$, $\mathrm{p}<.01$ (df corrected due to heterogeneity of variance)].

It was interesting to note that on the postsleep questionnaire (see Appendix H), subjects assigned the pleasant topics actually rated the topics as being significantly more pleasurable than did subjects assigned the unpleasant topics $[t(18)=4.10, p<.001$, two-tailed test $]$. on a comparison of only subjects controlling dreams, the ratings of those assigned pleasant topics were still found to be significantly higher $[t(11)=3.02, p<.02$, two-tailed test].

Computation of the association between the rated amount of pleasantness in the assigned topics and REM density indicated small but positive relationships for both all subjects $(r=.10, N=20)$ and controllers only $(r=.27, N=13)$. This indicated that as topic pleasantness increased, so did the amount of eye movement activity. It was also found that for both all subjects and controllers only, as more dreams were controlled, REM density decreased $(r=-.37, \mathrm{~N}=20$; and $r=-.48$, $\mathbf{N}=13$; respectively).

Finally, the author was curious ir: knowing if the dreams of the unpleasant-topic controllers were any more or 
less dreamlike than those of subjects assigned pleasant topics. A two-tailed $t$ test showed the unpleasant-topic controllers were slightly higher on DLQ, but this "dreaminess" difference was not significant $[t(11)=-1.56$, $\mathrm{p}<.20]$.

The above results indicated that the unpleasantness of the topic, as determined both by an independent evaluation prior to the study and by subject ratings, had an effect on REM processes, particularly REM density. Furthermore, the perceived pleasantness of the assigned topic appeared to have more of an effect than did just the successful attempt to manipulate dream content.

Postsleep Questionnaire and Interview

The postsleep questionnaire and subject reconstructions of the methods used in attempting to manipulate dream content failed to reveal any differences either between the training and control groups (with the exception that the training group used the self-instruction sequence), or between dream controllers and noncontrollers. One notable comparison was that involving subject evaluations of the three hours of training. The control group subjects rated the training in content manipulation as being only slightly less effective than did subjects from the training group $[t(15)=-1.46, p<.20$, two-tailed test (data available for only 17 subjects)]. Apparently the control group actually considered that training in content control had been provided. 
Pilot work had suggested that the amount and degree of dream control for the attention-placebo control subjects might vary depending on whether a verbal or imaginal encoding procedure of the dream topic was employed. Although it was found that the two subjects whose attempts essentially consisted of verbally repeating the topic suggestion failed to control any dreams, there were three other control group subjects reporting to have used some form of imagery in attempting content manipulation but were still unable to dream on the assigned topic.

There was no clear-cut indication that use of the self-instruction sequence before sleep would result in a manipulated dream. Although eight subjects in the training group did use the sequence on the posttest night of sleep and were able to control at least one dream, there were two subjects also using the sequence but unable to control any dreams. Further, the postsleep interview failed to uncover any noteworthy differences between training group controllers and noncontrollers in the way the sequence was employed. Training group subjects had been requested to return assignments documenting use of the sequence at home, but very few of these assignments were returned and no statistical analysis was attempted. Finally, it was noted that neither the training nor control group reported much of a change in controlling 
home dreams. Four subjects in the training group indicated a slight increase in the level of home control, and two subjects in the control group reported a similar change.

\section{Screening Measures}

Two-tailed $t$ test comparisons between the control and training subjects revealed that the groups were comparable on the measures of imagery vividness and visual imagery control (as assessed by the Betts and Gordon tests, respectively), home recall, previous dream content control, and age (see Table V). Subjects in each of the two groups scored in the higher ranges on both the Betts and Gordon and were moderate recallers. The absence of a significant difference on any of these selection measures indicated the groups entered the study on an equal basis and that these variables cannot account for any differences on the dependent variables.

It is interesting to note in Table $\mathrm{V}$ that the largest difference between the two groups was found on the initial measure of home recall, with the training group reporting to be slightly, although not significantly, better recallers. However, the same measure taken the morning following the posttest night of sleep showed absolutely no difference between the groups. This indicated that for at least a period of two weeks prior to the posttest night, both groups had been doing equally well in recalling home dreams and would have been expected 
TABLE V

SCREENING MEASURES

\begin{tabular}{|c|c|c|c|c|c|}
\hline \multirow{2}{*}{ Measure } & \multicolumn{2}{|c|}{$\begin{array}{l}\text { Group I: } \\
\text { Attention } \\
\text { Placebo } \\
\text { Control }\end{array}$} & \multicolumn{2}{|c|}{$\begin{array}{l}\text { Group II: } \\
\text { Cognitive- } \\
\text { Behavioral } \\
\text { Training }\end{array}$} & $\begin{array}{l}\text { Two-Tailed } \\
t \text { Test: } \\
\text { (Group I - } \\
\text { Group II) }\end{array}$ \\
\hline & $\begin{array}{l}M \\
S D\end{array}$ & $\begin{array}{l}=9.70 \\
=2.83\end{array}$ & $\begin{array}{l}M \\
S D\end{array}$ & $\begin{array}{l}=10.20 \\
=1.40\end{array}$ & $-.50 \mathrm{n} . \mathrm{s}^{\mathrm{a}}$ \\
\hline Betts : & & & & & \\
\hline a. Visual & & $\begin{array}{l}=11.70 \\
=5.54\end{array}$ & $\begin{array}{l}\mathrm{M} \\
\mathrm{SD}\end{array}$ & $\begin{array}{l}=13.10 \\
=7.91\end{array}$ & -.46 n.s. \\
\hline b. Total & $\begin{array}{l}M \\
S D\end{array}$ & $\begin{array}{l}=87.40 \\
=30.67\end{array}$ & $\begin{array}{l}\mathrm{M} \\
\mathrm{SD}\end{array}$ & $\begin{array}{l}=90.70 \\
=35.39\end{array}$ & $-.22 \mathrm{n} . \mathrm{s}$ \\
\hline \multicolumn{6}{|l|}{ Recall: } \\
\hline a. Initial & $\begin{array}{l}\mathrm{M} \\
\mathrm{SD}\end{array}$ & $\begin{array}{l}=3.20 \\
=1.62\end{array}$ & $\begin{array}{l}\mathrm{M} \\
\mathrm{SD}\end{array}$ & $\begin{array}{l}=4.40 \\
=1.84\end{array}$ & -1.56 n.s. \\
\hline b. Postsleep & $\stackrel{\mathrm{M}}{\mathrm{SD}}$ & $\begin{array}{l}=4.60 \\
=1.90\end{array}$ & $\begin{array}{l}\mathrm{M} \\
\mathrm{SD}\end{array}$ & $\begin{array}{l}=4.60 \\
=1.84\end{array}$ & .00 \\
\hline Age & $\begin{array}{l}\text { M } \\
\text { SD }\end{array}$ & $\begin{array}{l}=28.10 \\
=9.80\end{array}$ & $\begin{array}{l}\mathrm{M} \\
\mathrm{SD}\end{array}$ & $\begin{array}{l}=24.50 \\
=4.88\end{array}$ & $1.04 \mathrm{n.s}$. \\
\hline $\begin{array}{l}\text { Previous } \\
\text { Control }\end{array}$ & $\begin{array}{l}M \\
S D\end{array}$ & $\begin{array}{l}=2.10 \\
=\quad .88\end{array}$ & $\begin{array}{l}M \\
S D\end{array}$ & $\begin{array}{l}=2.30 \\
=.82\end{array}$ & $-.53 \mathrm{n.s.}$ \\
\hline
\end{tabular}

$a_{\text {not significant }}$ 
to recall laboratory dreams at a comparable level. It was also interesting that while there was little change in home recall for the training subjects, the control group reported a significant increase in the number of home-recalled dreams $[t(10)=2.94, p<.02$; two-tailed, repeated measures test]. Further examination of the postsleep measure of reported recall showed, on two-tailed $t$ tests, there was no significant difference between the controllers and noncontrollers $[t(18)=1.10, p<.50]$ or between unpleasant and pleasant-topic controllers $[t(11)=.65, p<.80]$. 
CHAPTER VII

\section{DISCUSSION}

\section{Content Control}

The cognitive-behavioral training method tested in this study produced little effect on the number or proportion of controlled dreams for a select group of subjects high in imagery vividness and visual imagery control and already reporting some incidence of previous dream control. However, since content control did occur, with $80 \%$ of the training group subjects controlling at least one dream and $50 \%$ of the control group doing likewise, it is worthwhile contrasting the results of this experiment with some earlier laboratory work.

The training group examined alone revealed that $23 \%$ of the awakenings resulted in a controlled report. Although there has been no previous research using the same training procedure and experimental design, the effects of the training may be compared with the research employing hypnotic suggestions. Tart (1964) found $26 \%$ of REMP awakenings resulted in reports containing portions of a suggested narrative and were produced by 50 of a group of hypnotized subjects. Barber, Walker and Hahn 
(1973) found controlled reports in $30 \%$ of the awakenings of hypnotized subjects directed to dream on a specific topic. These latter investigators made a distinction between dreams and other thoughts occurring during sleep and showed that $19 \%$ of the subjects presented at least one dream containing elements of the suggested topic while $62 \%$ of the hypnotized group produced at least one thought report of the topic. A somewhat larger effect with the use of hypnosis was reported by Stoyva (1965) in a study showing $66 \%$ of the total awakenings to have resulted in controlled dreams and were presented by $88 \%$ of the subjects.

The total number of dreams controlled by the training and control groups combined was relatively small with 16 (20\%) of the awakenings yielding a controlled dream and being reported by $65 \%$ of the subjects. Again, due to methodological differences between the present study and previously published research, it is difficult to contrast these findings with other content control results. However, in the only other study using comparison groups, the data are similar. Barber's et al. (1973) well-controlled work showed $24 \%$ of the laboratory awakenings resulted in controlled reports from subjects given either hypnotic or nonhypnotic suggestions to dream on a specific topic. Again, distinguishing between dreams and thought reports, these experimenters found that $25 \%$ of the subjects pro- 
duced at least one controlled dream and $42 \%$ were able to present one or more thought reports on the assigned topic.

The comparisons between the control and training groups revealed nodifferences in either the number or proportion of controlled dreams. Barber et al. (1973) also found no difference in the number of controlled dreams for subjects receiving either hypnotic or nonhypnotic suggestions. However, these researchers did find the hypnotized subjects to report significantly more thoughts containing elements of the suggested topic.

That the controlled dreams did not consistently appear in any one particular REMP of the posttest night and were fairly evenly distributed throughout the night for each group is consistent with the observations of Tart and Dick (1970). This indicated there was not any one good time or a certain REMP which would be most likely to result in a dream containing the assigned topic, and the presleep instructions were distinct enough to be remembered throughout the night.

Thus, the findings of this study are in line with earlier research on content manipulation. One conclusion which may be reached is that the effectiveness of the training method usea here was comparable to results obtained with hypnotic procedures. Also, while most of the earlier research has failed to utilize control groups, the 
inclusion of the attention-placebo group in the present study allowed comparisons to be made and provided the perspective needed in content control work.

\section{Degree of Control}

The data showed the training group was significantly higher on TR and indicated the dreams of this group more closely reflected the object and action of the assigned topics than did the dreams of the control group. Thus, the training method did substantially increase the extent to which the dreams were controlled, at least on this variable. It is notable that this measure is similar to the density score used by Barber et al. (1973). These experimenters found no difference between hypnotized and nonhypnotized subjects on the density of dream reports but did find the density score of thought reports to be significantly greater for the hypnotized group.

There was no difference in the amount of PI between the two groups, but the questionable interrater reliability on this variable points to some difficulty with the scoring system and renders the results of this measure relatively meaningless. Although the difference on MC was significant and approached significance on SIC, the results on these two degree of control variables are rather difficult to decipher. It is to be remembered that SIC measured content changes, and it was hypothesized that a change from some content area to the assigned topic would 
be indicative of a higher level of control. This notion of a content shift parallelled the change from the unrelated imagery to the dream topic imagery which was practiced in the self-instruction sequence. The dreams of the training group were found to contain this shift slightly more often than those of the control group, and this meant the control group subjects started dreaming of the assigned topic immediately. That the dreams of the training group had this shift suggests the use of the sequence had some impact; however, as the control group had not been instructed to practice this change in imagery, it could be argued that the dreams of these subjects showed a slightly higher degree of control because they closely followed the instructions to dream on the assigned topic without the direction to recognize and change an already occurring dream. The obvious question then is, is more control reflected by a shift in content or by immediately dreaming on the assigned topic? This question does not appear to be answerable on the basis of the results found in this study because the two groups were apparently attempting different tasks. Closer inspection of the training procedure and instructions given on the posttest night of sleep reveals that the training group was asked to exercise concurrent dream control while the group was tested on presleep control. If the SIC variable is interpreted as a measure of concurrent control, then the 
training group appears to have done slightly better at recognizing the occurrence of dream imagery, and there are indications that such a capability does in fact denote a high level of control (e.g., lucid dreaming; Garfield, 1974). Since the control subjects were not requested to make this recognition (i.e., attempt concurrent control), it cannot be concluded that they showed any greater or, even more importantly, any less control on SIC. This also means that the significant results on MC may also not be an accurate assessment of degree of control because this was a measure obtained by combining SIC and TR scores. Further, due to the rather high intercorrelation with TR, it would appear that MC did not provide much more information on degree of control beyond that which was measured by TR.

It is of interest to note the similarity between SIC and lucid dreaming, especially considering the indication that the training group was exhibiting some concurrent control capability. A clear example of an attempted switch in content is shown in the following portion of a third REMP report from a training group subject assigned the topic of Fighting in a War:

... and all of a sudden there was a parade coming up. It was only a small parade, but I felt. . kind of like we were cut off from their house. . . by the paracie, which. . . which in fact we were. Then. - the parade passed and your assistant came in again. . . taking all the wires off my head. - and. . I was still really, really trying to get a war picture going in my head, 
and I was saying, "Oh, you can't, you can't do it! I haven't dreamed of war yet! I haven't dreamed of war yet" . . . and I was trying to make all of my war images come in and then. . . he was just about finished packing up and. . . and I was out of bed. I had put this by. . gotten dressed and everything else, and I was still thinking, "War, war, war! I've got to think of wars!" . . and that's when you rang the buzzer, and that's what I was thinking just as you rang the buzzer.

Although this particular subject did not actually dream of fighting in a war, it is apparent that an attempt was being made to change the content to the assigned topic. This report is similar to some anecdotal reports given by training group subjects. These subjects observed that when sleeping at home, just as a dream was to be directed to a desired topic, they would awaken without having dreamed of the topic or experiencing any of the topic imagery. This phenomenon is comparable to that of lucid dreaming (Garfield, 1974). In a lucid dream, the dreamer becomes aware of the experience of dreaming and can then direct the content of the dream. A difficulty that is frequently encountered with lucid dreaming, especially for people just starting to develop this capability, is that the awareness of dreaming often triggers the sleeping individual to awaken. Unfortunately, none of the subjects controlling dreams during the posttest night were ever queried whether or not there had been an awareness of dreaming before the dream was directed to the assigned topic. 
Self-Instruction Sequence

There were three sets of imagery involved in the self-instruction sequence used by the training group: cuing imagery, dream topic imagery, and covert reinforcement imagery. Surprisingly few dreams from the training group reflected either the cuing or reinforcement imagery In one controlled dream, the object of the assigned topic became an object of the reinforcer. The subject had been given the topic of Finding Money, and an image of taking a relaxing bath while listening to music and drinking tea was used as the reinforcer. This subject reported the following as part of a third REMP-awakening dream:

I was walking. . . I was coming away . . it's coming back from somewhere. Maybe... because my sister had left with all these cousins to drive them somewhere, and I was coming back and all these people were .. . dancing to this kind of Christmas music, and I went to sit at my table and there were all these people there so I went and sat in a booth . . nearby, and . . . this one person . . think it was a lady... walked over and handed me something, and it... and I thought. . "Did I leave some money there? Money or what?" . . . 'cause I couldn't imagine what she was bringing me unless it was a quarter, but it was a teabag.

In this dream, a portion of the reinforcer followed the object of the assigned topic. It should be noted that this coincides with the order of covert events used in the sequence. T'wo other controlled dreams from the training group suggested possible incorporation of non-topic imagery from the sequence, but in neither case was this very clear. 
Also, none of the uncontrolled dreams contained any non-topic imagery. Thus, if the subjects reported dreams containing any of the imagery used in the sequence, it was most often the imagery of the assigned topic only. This would indicate that the self-instruction sequence did, in fact, assist the subjects in dreaming on the assigned topic. If dreaming on a selected topic was only a matter of thinking or imagining the topic while awake, all three sets of imagery used in the sequence should have had an equal probability of being incorporated into the dreams. As the non-topic imagery was rarely found in controlled dreams and not at all in uncontrolled dreams, it is considered the sequence did facilitate the performance of a covert behavioral response.

It is difficult to decipher the effects of the covert reinforcer used in the sequence because it is not entirely clear what exactly was being reinforced. Was it the response to change the dream to a selected topic or was it really reinforcing the rehearsal of the whole sequence? This question cannot be answered for certain on the basis of the present study. Two of the training group subjects did report awakening at home to discover having been rehearsing the whole sequence while asleep. However, as there was no way of determining during which sleep stage this occurred and because, as indicated above, this phenomenon did not occur during the posstest night, 
it would appear that it was the response of directing the dream to the assigned topic which was being reinforced and not the sequence rehearsal.

\section{REM Processes}

It was previously noted that although this study did not set out to examine REM processes, the amount of pleasantness in the assigned topic was found to educe an effect in this area. None of the earlier work in content control has focused exclusively on process effects due to the desirable (or undesirable) nature of a suggested topic, and the small amount of published research which has examined the relationship between REM processes and presleep instructions has yielded conflicting results. Stoyva (1965) found a small overall reduction in REM time for subjects dreaming on a hypnotically suggested topic, but the pleasantness of the topic did not appear to be a major factor in this effect. (This latter observation was, however, based only on 1 out of 16 subjects.) Stoyva implied that if a posthypnotic suggestion was effective and subjects did dream on assigned themes, there would be a reduction in REM time. In contrast to this, Albert and Boone (1975) noted reductions in 8 REM time for 2 out of 5 subjects given an unpleasant posthypnotic suggestion not to dream, but normal amounts of $\&$ REM were found in subjects presented a pleasant posthypnotic suggestion to dream as much as possible. Thus, it was not 
just compliance with the suggestion which elicited reductions in REM time, but rather topic pleasantness did appear to be a factor in these reductions. Ogilvie et al. (1975) found 8 REM time to be unaffected by nonhypnotic suggestions to either increase or decrease subjective dreaming time, but the amount of REM activity indicated changes in accordance with the suggestion to increase (but not decrease) dreaming time. In a later study, Ogilvie et al. (1978) failed to note any changes in REM density (number of REMs per REMP) in accordance with requests to either increase or decrease the amount of emotional involvement in dreams.

The results of the present study were more in agreement with the earlier work of Ogilvie et al. (1975) in that 8 REM time remained intact regardless of whether or not any dreams were controlled and was unaffected, with the exception of the comparison of 8 REM time accounted for by the REMP leading to a controlled dream, by the emotional tone of the assigned topic. However, REM density, especially on comparisons of subjects manipulating dreams, did appear to be affected by the pleasantness of the topic, and it may be that this measure, unlike 8 REM time, is sensitive enough to detect differences such as the rated pleasantness of a dream topic.

Due to the dearth of previous research on content control and also the manner in which the pleasantness of 
the presleep topic affected REM density in the present study, it is difficult to account for the density-pleasantness relationship. Perhaps the more unpleasant topics created more anxiety or presleep stress for the sleeping individual than did the pleasant ones. Although no measure of anxiety or stress was obtained from the subjects, either after assignment of the topic or after a dream report was provided, and judges were not requested to rate the reports on emotionality, topics which had been rated low on pleasantness did appear to produce some negative emotionality in dreams. Four examples of dream reports received from subjects assigned unpleasant topics are presented below, with the first three reports elicited from subjects rating the topic pleasantness at 0 (no pleasure at all) and the final report coming from a subject rating the amount of pleasure in the topic at 1 (a little pleasure):

He was being attacked by these machine gunners, like rebels, who were overthrowing this village, and he . . he came attacking them with some sort of hand-to-hand combat but he was mutilated. (Portion of a third REMP awakening for the topic, Fighting in a War.)

I was skiing and. . real fast. . . real straight... it's a direct line right down . . a hill. . . then I. . . was trying to get these skis into a closet, and I couldn't 'cause $I$ was just cramming them in any old which-way. They wouldn't... I wasn't . . I was trying to force them in .. . sideways. I was going fast... straight and short, like off a page... not a soul around. (Portion of a second REMP awakening for the topic, Being Locked in Jail.) 
Oh! I thought I had a. . . just a terrible headache. In fact, I . . I don't have a headache at all, I thought I did though. I . . I don't know, it was like... it was, everything has very few images. It's like. . . physical tonight. I thought I was real thirsty and I. . I couldn't move. I was just like . . really oppressed or something. . . I was laying down. I couldn't get up. I remember one time I . . felt like I just couldn't move, but, I mean, it was also.. . the physical feeling of . . of dead weight, but it was also a mental feeling. I just. . . like my mind was stripped, I was dull . . and it's... it's hard to explain 'cause I . . there was - . there was no lightness, no feelings of anything except just . . . depression type. (Portions of a third REM awakening for the topic, Being Locked in Jail.)

. . it just wasn't a very good feeling . . in . . . it was kind of frustrating to me, especially 'cause I didn't want to be in there either. I wanted to get out. . . too, but. . not enough of 'em wanted to so we could get out and do something... there on campus. It was . . . dark outside and . . . it was . . it was raining . . (Portion of a fourth REMP awakening for the topic, Being Locked in Jail.)

Assuming the pleasantness ratings of the assigned topics were an indication of anxiety or presleep stress, it is possible that the unpleasant topics produced a lesser amount of REM density due to the heightened level of negative emotionality elicited by these themes.

If, in the present study, ratings of topic pleasantness were indicative of stress, the results were contrary to earlier findings showing presleep stress: to cause an increase in eye movements during REM sleep (Baekeland, Koulack \& Lasky, 1968; Cohen, 1975). If the 
pleasantness ratings denoted the amount of anxiety in the dreams produced by the topic, the present results were again opposite to what would be anticipated on the basis of prior work. For example, Fisher, Byrne, Edwards and Kahn (1970) monitored the sleep of subjects reporting frequent REM anxiety dreams (nightmares) and found that in 12 out of 20 nightmares, there were neither increases nor decreases in eye movement activity; however, 8 out of 20 REM anxiety dreams had increases in the number of eye movements, with 3 of the most severe showing increases from 2 to 13-14 REMS. Goodenough, Witkin, Koulack and Cohen (1975) also found the number of REMs to be higher during REMPs which led to dreams rated high in anxiety. Finally, in the present study, small but positive correlations between the pleasantness ratings and REM density were found for both controllers $(r=.27)$ and all subjects $(r=.10)$. If the pleasantness ratings were indicative of anxiety or presleep stress then, according to the above earlier research, as topic pleasantness increased, REM density should have decreased rather than increased.

Therefore, there would appear to be three possible explanations for the present results on REM density: (1) The pleasantness ratings of the topics were independent of experienced anxiety or presleep stress. This is a good possibility because there were no attempts made, 
either prior or during the study, to determine the extent to which the question used for the rating was associated with this negative emotionality. Also, in light of the earlier research, the rather meager correlations between topic pleasantness and REM density would suggest that the pleasantness rating may had nothing to do with presleep stress or anxiety. (2) The unpleasant topics actually did elicit more anxiety or stress and produced decreases in eye movement activity. Although this is a feasible proposition, the results of earlier work has indicated that negative emotionality produces increases in eye movements. (3) The pleasant topics produced more anxiety or presleep stress in the subjects. This explanation would be in accordance with prior research, but it would appear illogical that pleasant topics would cause such negative emotionality. Further, this final possibility would suggest that the subjects assigned the unpleasant topics enjoyed attempting or actually having a "bad" dream. With the above in mind, it is proposed that the final explanation may really be the most accurate interpretation of what occurred, especially when a distinction is made between presleep stress and anxiety. The author proffers such a distinction between the two by focusing on the source of negative emotionality involved in this study of dream. control: 
Presleep Stress - negative emotionality due to pressure (self or other produced) to dream on an assigned topic.

Anxiety - negative emotionality associated with an experienced dream.

Differentiating between presleep stress and anxiety in this manner, it is hypothesized that assignment of both pleasant and unpleasant topics produced substantial amounts of presleep stress in all subjects. (There were no baseline data available to substantiate this; however, this stress-inducing effect of presleep instructions is consistent with the suggestions of Ogilvie et al., 1978.) One way to reduce this stress would be to successfully control a dream, and the unpleasant topics, due to being unique and not of matters one would typically choose to dream about, were easiser topics to control than were the pleasant ones. Further, any anxiety associated with an experienced dream would thus be offset by the successful manipulation of the dream and compliance with the presleep instructions. An indication of the validity of this hypothesis may be found in the correlations between the number of dreams controlled and REM density. Although quite small, negative correlations were found for both controllers only and for all subjects $(r=-.48$ and $r=-.37$, respectively) and showed that as the subjects produced more controlled dreams, REM density decreased.

A supple- 
mentary indicator that this was actually what occurred may be found on the REM density comparison between controllers and noncontrollers. This difference was nonsignificant but in a direction showing that the noncontrollers had a higher level of REM density $[t(18)=-1.01, p<.40$, two-tailed test]. Thus, the present results would be consistent with earlier research on the effects of presleep stress and possibly even anxiety.

It should be obvious that the above is at best an hypothesis which attempts to draw together the data from an area for which this experiment was not designed. However, the observations made here would suggest the need for further, more extensive inspection of the relationship between topic pleasantness and REM density in content control research. Additionally, if the noted effects of REM density were due to either presleep stress or an interaction of presleep stress and anxiety, future research in this area could uncover important information on how everyday stress and/or dream anxiety is normally handled and, possibly, how it may even be better controlled in REM sleep.

Before leaving this section on REM processes, the author feels compelled to briefly address and dismiss one final explanation related to the noted differences in REM density. Antrobus, Dement and Fisher (1964) reported that recallers spent significantly more time in REM 
sleep than did nonrecallers, but recallers had significantly fewer eye movements. Thus, could it have been that the difference in REM density between unpleasant and pleasant-topic controllers was really only a matter of recal1? The data indicated that such was not the case. Firstly, the level of reported recall taken from the postsleep questionnaire failed to distinguish between those controlling unpleasant and pleasant topics. This in itself would indicate that, contrary to what actually resulted, there should have been no differences in REM density. Secondly, the differences between pleasant and unpleasant controllers on comparisons of 8 REM were observed to be in directions opposite to what should have resulted if reported recall had been a factor. 
CHAPTER VIII

FINAL REMARKS

The present study found some limited support for the cognitive-behavioral training method used to develop dream control capability and noted the emotional tone of the assigned topics appeared to affect REM density, especially for individuals controlling dreams. It is considered that further content control research, in areas of both the training procedure and the relationship between topic pleasantness and REI processes, is suggested by the results of this study. The purpose of this final chapter is to point out some difficulties with this study and to provide suggestions for subsequent experimental designs and training procedures.

Dream research is an expensive and extremely time consuming endeavor. Limitations in equipment and money in the present study resulted in an experiment which was less elegant and precise than is really needed for this type of work. Contrary to the recommendations of Rechtshaffen and Kales (1968), only one channel was used to monitor eye movements and recordings of muscle tension (EMG) were omitted. Because the EMG could not be monitored, sleep and REMP onset determinations could only be approxi- 
mated. The author was also the only person involved with the experiment, and this meant the training, sleep monitoring, subject interviews, and analysis of the physiological tracings were all done by the same person. Although the author is aware of the effects of demand characteristics and experimenter expectations and worked to adjust the experiment to account for these factors, their possible influence on the final results is openly acknowledged.

No attempts were made to account for the type of encoding procedures used in the content manipulation efforts of the attention-placebo control group. As was noted earlier, two subjects used only verbal self-suggestions while the other eight employed visual imagery techniques, some even approximating the self-instruction sequence. On the basis of pilot work, it had been anticipated that more of the control group subjects would rely solely on verbal self-suggestions and dream control differences would be found due to the techniques employed. However, use of the two imagery questionnaires in selecting subjects may have provided cues for most of the control group to utilize imagery on the posttest night of sleep, and this precluded any differential effects or trends from being observed. Future research similar to the present study, in which the types of encoding methods used by control subjects prior to sleep onset are closely monitored, could reveal variations in content control levels. 
It was noteworthy that both judges agreed upon a substantial number of incorrect report-topic matches $133 \%$ of all reports). It should also be remembered that the subjects had no knowledge of the topics which were not assigned. Thus, with the topics used, one-third of the reports represented "natural" or "accidental" dreams of unassigned topics. This is a problem in content control research which has often not been accounted for but would appear to be important when, as in this study, multiple topics are to be used. Obviously, another comparison group would have been helpful in controlling for this "accidental manipulation."

No differences were found for the dream-like quality measure on comparisons of dreams for the control versus training group, controllers versus noncontrollers, and unpleasant versus pleasant-topic controllers. However, it might have been informative to have distinguished between thought and dream reports, and it would seem very appropriate to do so in a larger study involving more posttest nights of sleep. It has also been argued that REM sleep is not a homogeneous period (Pivik, 1978; Price \& Kremen, 1980), and tonic and phasic awakenings from this state may result in report differences similar to those produced from NREM and REM awakenings, respectively (Goodenough et al., 1975). Therefore, a separation of thought and dream reports obtained from REM sleep could have potentially resulted in a more precise and sensitive content control indicator. 
The scoring system for degree of control was one which had not been used in any previous work, and the interrater reliabilities on PI and SIC indicated further refinements of this system are in order for at least these two variables. It is believed that the varying aspects of the reports which were taken into account with this scoring method did provide a unique and useful approach in determining the level of control. It is further considered that because the system is fairly straightforward and much simpler to use than some other rating devices, at this stage it is worthy of further inspection and changes rather than total abandonment.

An obvious question to consider at this time is why the cognitive-behavioral training procedure wasn't more effective in developing and enhancing content control capabilities. Although it is difficult to determine this from the present study, some observations suggested areas which provide some clues and could prove valuable in future research along these same lines. These observations are discussed in reference to the four component processes of the cognitive-behavioral model which was presented earlier in this paper.

1. Attention. Only one night was used to test content control capabilities of the subjects. The idea of a "learning effect" resulting from the use of more laboratory nights has been suggested by Tart and Dick (1970), and it 
is possible that with more than one test night, such an effect may have been noted for all the subjects or enhanced only the techniques used by the training group. It is of interest that one training group subject, controlling two out of three dreams, considered the posttest night awakenings to provide a form of feedback. This subject used the performance information to readjust the sequence accordingly and then practiced it before returning to sleep.

The notion of employing more laboratory nights leads to a consideration of the increased effectiveness which might be found if laboratory sleep were actually included as part of the training procedure. A major underlying assumption in the present study was that subjects could learn to discriminate between the types of cognitive activity (i.e., preceptual versus conceptual thinking) occurring during sleep through the use of a covert procedure in the waking state. Earlier research had shown that subjects, without any prior training, could discriminate and signal the occurrence of a dream and could do so without awakening (Antrobus et al. 1965; Brown \& Cartwright, 1978). However, Salamy (1970) found that the recognition of a dream and response of signalling the experimenter could be enhanced using a negative reinforcement procedure: if a subject had not signalled within three minutes of REMP onset, the sleeping individual was awakened and kept 
from falling back asleep for a period of four minutes. It is possible that the inclusion of a similar operant procedure in the present study may have enhanced the effects of the self-instruction sequence. It may well have been that discriminating dreams from other cognitive events was more difficult than anticipated with the use of only a covert procedure in the waking state. Also, laboratory training involving the pairing of some external stimulus with specific content might in itself be a valuable beginning in developing content manipulation capability. A procedure similar to this is reportedly being examined by Antrobus (1978) .

It is conceivable the discrimination between perceptual and conceptual types of mental activity could have been facilitated through the use of both REM and NREM awakenings (or possibly awakenings from tonic and phasic periods of REM sleep), especially if laboratory sleep had been included as part of the training. It is difficult to say, given how the present study was conducted, that such discriminations were in fact made by the training group. Although a few NREM awakenings were made in the training group, either by accident or because the subject was in such a sleep stage at the predesignated final-awakening time, none of these indicated the subject had dreamed or was attempting to dream on the assigned topic. However, instead of the scheduled REM awakening times, a more 
consistent attempt to include REM and NREM awakenings (or tonic-phasic awakenings) may have provided a more effective means both of training the subjects to distinguish dreams from other mentation and in determining whether or not this discrimination had actually been learned.

2. Retention. Subjects in the training group invariably reported that practice of the sequence was probably the most crucial element in the training. The length of training was very short, only two weekly sessions of $1 \frac{1}{2}$ hours each, and for the training group this meant that very little time could be spent practicing and monitoring usage of the sequence during the small group meetings. Some subjects admitted the meetings constituted the majority of time that had been devoted to rehearsing the sequence. Also, it was considered that in using dreaming as a discriminative stimulus to direct further dreaming, subjects were acquiring a new behavior. Because changes in behavior or the acquisition of new responses in the waking state often take periods longer than two weeks, expectations that the training would provide dramatic results may have been unrealistic. This is further suggested by noting that when similar behavior change techniques are used in a clinical setting, training or treatment is rarely completed in two sessions and alterations in behavior are seldom found to occur overnight. 
3. Component Behaviors. Subjects chosen for participation in this study were those showing higher levels of imagery vividness and visual imagery control. Such a select group was used because it was considered these factors would be crucial in the development of dream control capability. It is still maintained that these factors are important, but it is disputable whether or not the questionnaires used provided a valid indication of them. It may also be necessary to identify additional dimensions, such as subject suggestability, for at least the initial developmental stages of a training approach similar to the one used here.

4. Incentive Conditions. The contribution of the covert reinforcement procedure used in the self-instruction sequence is another area which is difficult to assess. Although the use of this technique has yielded positive results in various clinical situations (Cautela, 1970; Guidry, 1974; Lott, 1975), the role and effectiveness of the covert reinforcing stimulus is questionable (Mahoney, 1974; Hurley, 1976). It is also possible that in the present study, the reinforcers chosen by the subjects were only moderately effective. Perhaps content control and the degree of control would have increased with the use of more potent covert reinforcers or could have been enhanced with the addition of some form of external reinforcement. 
In conclusion, this exploratory study approached the area of dream content control within the framework of the cognitive-behavioral model. Such a study had not been previously attempted because the area of dreams, in general, has been avoided by most behavioral psychologists. The effectiveness of the training procedure used here was of a limited nature, but the above discussion may provide some guidelines in how the development of content control may be approached with a similar technique and still within the confines of the cognitive-behavioral perspective. It is considered that further research is suggested by the results of this experiment. Such work could prove valuable not only for the purely experimental inquiry on dream control and REM processes, but also for clinical situations (e.g., treatment of nightmares) and everyday applications (e.g., stress reduction). Perhaps with finding an effective means of developing dream control, this area of human "nightlife" would become better understood and similar to normal, waking thought in accessibility and productivity. 


\section{REFERENCES}

Albert, I. B. and Boone, D. Dream deprivation and facilitation with hypnosis. Journal of Abnormal Psychology, 1975, 84, 267-271.

Antrobus, J. S. Dreaming for cognition. In A. Arkin, J. Antrobus and S. Ellman (Eds.), The Mind in Sleep: Psychology and Psychophysiology. Hillsdale, N. J.: Lawrence Erlbaum Associates, 1978.

Antrobus, J. S., Antrobus, J. S. and Fisher, C. Discrimination of dreaming and nondreaming sleep. Archives of General Psychiatry, 1965, 12, 395-401.

Antrobus, J. S., Dement, W. and Fisher, C. Patterns of dreaming and dream recall: An EEG study. Journal of Abnormal and Social Psychology, 1964, 69, $341-344$.

Aserinsky, E. and Kleitman, N. Regularly occurring periods of eye motility, and concomitant phenomena, during sleep. Science, 1953, 118, 273-274.

- Two types of ocular motility occurring in sleep. Journal of Applied Physiology, 1955, 8 , $1-10$.

Baekeland, F., Koulack, D. and Lasky, R. Effects of a stressful presleep experience on electroencephalographrecorded sleep. Psychophysiology, 1968, 1, 436-443.

Baekeland, F., Resch, R. and Katz, D. Presleep mentation and dream reports: I. Cognitive style, contiguity to sleep, and time of night. Archives of General Psychiatry, 1968, 19, 300-311.

Bandura, A. Social Learning Theory. Englewood Cliffs, N. J.: Prentice-Hall, 1977.

Barber, T. X., Walker, P. C. and Hahn, K. W. Effects of hypnotic induction and suggestions on nocturnal dreaming and thinking. Journal of Abnormal Psychology, 1973, 82, 414-427. 
Beck, A. T. Dreams as compared to other forms of fantasy: Discussion. In M. Kramer (Ed.), Dream Psychology and the New Biology of Dreaming. Springfield, IIl.: Charles Thomas, 1969 .

Bergin, A. E. A note on dream changes following desensitization. Behavior Therapy, 1970, 1, 546-549.

Brown, J. N. and Cartwright, R. D. Locating NREM dreaming through instrumental responses. Psychophysiology, $1978,15,35-39$.

Cartwright, R. D. Dreams as compared to other forms of fantasy. In M. Kramer (Ed.), Dream Psychology and the New Biology of Dreaming. Springfield, Ill.: Charles Thomas, 1969.

- Nightlife: Explorations in Dreaming. Englewood Cliffs, N. J.: Prentice-Hall, 1977.

Cautela, J. R. Behavior therapy and the need for behavioral assessment. Psychotherapy: Theory, Research, and Practice, 1968, 5, 175-179.

- Covert reinforcement. Behavior Therapy, $1970^{\circ}, 1,33-50$.

Cavior, N. and Deutsch, A. Systematic desensitization to reduce dream-induced anxiety. The Journal of Nervous and Mental Diseases, $19 \overline{75,161}, 433-435$.

Cohen, D. B. Toward a theory of dream recall. Psychological Bulletin, 1974, 81, 138-154.

- Eye movements during REM sleep: The influence of personality and presleep conditions. Journal of Personality and Social Psychology, 1975, 32, 10901093.

Craighead, W. E., Kazdin, A. E. and Mahoney, M. J. Behavior Modification: Principles, Issues, and Applications. Boston: Houghton Mifflin, 1976.

Dement, $w$. and Kleitman, $N$. The relation of eye movements during sleep to dream activity: an objective method for the study of dreaming. Journal of Experimental Psychology, 1957, 53, 339-34 6 .

Dement, W. and wolpert, E. A. The relation of eye movements, body motility, and external stimuli to dream content. Journal of Experimental Psychology, 1958, 55, 543-553. 
Ellman, S. J., Bowe, C. and D'Aquini, T. A learning of the partial reversal of the REM sleep cycle with an intermittent-reinforcement schedule. Psychophysiology, 1969, 6, 237. (Abstract)

Ellman, S. J., Shollar, E., Rosenbaum, J. and Levine, B. The learning of a partial reversal of the sleep cycle. Psychophysiology, 1968, 4, 387. (Abstract)

Evans, I. N. and Kamemoto, W. S. Reliability on the short form of Bett's Questionnaire on Mental Imagery: Replication. Psychological Reports, 1973, 33, 281-282.

Fisher, C., Byrne, J., Edwards, A. and Kahn, E. A psychophysiological study of nightmares. Journal of the American Psychoanalytic Association, 1970, 18, 747-782.

Fiss, H. and Ellman, S. J. REM sleep interruption: Experimental shortening of REM period duration. Psychophysiology, 1973, 10, 510-516.

Foulkes, D. Dream reports from different stages of sleep. Journal of Abnormal and Social Psychology, 1962, 65, 14-25.

Theories of dream formation and the recent studies of sleep consciousness. Psychological Bulletin, 1964, 62, 236-247.

Foulkes, D. and Fleisher, S. Mental activity in relaxed wakefulness. Journal of Abnormal Psychology, 1975, 84, 66-78.

Foulkes, D. and Griffin, M. L. An experimental study of "creative dreaming." Sleep Research, 1976, $\underline{5}, 129$.

Freud, S. On Dreams. New York: W. W. Norton, 1952. (Originally published: Wiesbaden: Bergmann, 1901.)

- The Interpretation of Dreams. New York: Avon Books, 1965. (Originally published: Leipzig and Vienna: Franz Deuticke, 1900.)

Garfield, P. L. Creative Dreaming. New York: Simon and Schuster, 1974 .

Geer, J. H. and Silverman, I. Treatment of a recurrent nightmare by behavior-modification procedures: A case study. Journal of Abnormal Psychology, 1967, 72, $188-190$. 
Giora, Z, and Elam, Z. What a dream is. British Journal of Medical Psychology, 1974, 47, 283-289.

Goodenough, D. R., Witkin, H. A., Koulack, D. and Cohen, H. The effects of stress films on dream affect and on respiration and eye-movement activity during rapid-eye-movement sleep. Psychophysiology, 1975, $12,313-320$.

Granda, A. M. and Hammack, J. T. Operant behavior during sleep. Science, 1961, 133, 1485-1486.

Greenleaf, E. "Senoi" dream groups. Psychotherapy: Theory, Research and Practice, 1973, 10, 218-222.

Griffin, M. L. and Foulkes, D. Deliberate presleep control of dream content: An experimental study. Perceptual and Motor Skills, 1977, 45, 660-662.

Guidry, L. S. Covert reinforcement in the treatment of test anxiety. Dissertations Abstracts International, $1974,34(7-B), 3497$.

Hart, J. T. Dreams in the classroom. Experiment and Innovation: New Directions in Education at the University of California, 1971, $\underline{4}$, 51-66.

Hays, W. L. Statistics for the Social Sciences. New York: Holt, Rinehart and Winston, 1973 .

Hiscock, M. and Cohen, D. B. Visual imagery and dream recall. Journal of Research in Personality, 1973, 7, $179-18 \overline{8}$.

Hobson, J. A. and McCarley, R. W. The brain as a dream state generator: An activation-synthesis hypothesis of the dream process. American Journal of Psychiatry, $1977,134,1335-1348$.

Hurley, A. D. Covert reinforcement: The contribution of the reinforcing stimulus to treatment outcome. Behavior Therapy, 1976, $\underline{7}, 374-378$.

Johnson, L. C. Are stages of sleep related to waking behavior? American Scientist, 1973, 61, 326-338.

Juhasz, J. B. On the reliability of two measures of imagery. Perceptual and Motor Skills, 1972, 35, 874 .

Lindzey, C., Hall, G. S. and Thompson, R. F. Psychology. New York: Worth, 1973. 
Lott, S. J. B. A study of covert reinforcement as a treatment of test anxiety in male and female fifth graders. Dissertations Abstracts International, $1975,36(4-B), 2028$.

Mahoney, M. Cognition and Behavior Modification. Cambridge, Mass.: Ballinger, 1974.

Maultsby, M. C. and Gram, J. M. Dream changes following successful rational behavior therapy. Rational Living, 1974, 9 , 30-33.

McDonald, D. G., Shicht, W. W. , Frazier, R. E., Shallenberger, H. D. and Edwards, D. J. Studies of information processing in sleep. Psychophysiology, $1975, \underline{12}, 624-629$.

McKelvie, S. J. and Gingras, P. P. Reliability of two measures of visual imagery. Perceptual and Motor Skills, 1974, 39, 417-418.

Meichenbaum, D. H. Cognitive modification of test anxious college students. Journal of Consulting and Clinical Psychology, 1972, 39, 370-380.

Therapist manual for cognitive behavior modification. Unpublished manuscript, University of Waterloo, 1973 .

- Cognitive-Behavior Modification: An Integrative Approach. New York: Plenum Press, 1977.

News \& Comment. Human Nature, June 1978, p. 12.

Ogilvie, R., Belicki, K. and Nagy, A. Voluntary control of dream affect? Waking and Sleeping, 1978, $\underline{2}$, 189-194.

Ogilvie, R., Busby, K., Costello, L. and Broughton, R. The effects of presleep suggestion upon REM sleep. Canadian Journal of Behavioral Science, 1975, ㄱ, 139-150.

Osgood, C. E. The nature and measurement of meaning. Psychological Bulletin, 1952, 49, 197-237.

Osgood, C. E. and Suci, G. J. Factor analysis of meaning. Journal of Experimental Psychology, 1955, 50, 325-338. 
Pivik, R. T. Tonic states and phasic events in relation to sleep mentation. In A. Arkin, J. Antrobus and S. Ellman (Eds.), The Mind in Sleep: Psychology and Psychophysiology. Hillsdale, N.J.: Lawrence Erlbaum Associates, 1973.

Price, L. J. and Kremen, I. Variations in behavioral response threshold within the REM period of human sleep. Psychophysiology, 1980, 17, 133-140.

Rechtschaffen, A. and Kales, A. (Eds.) A Manual of Standardized Terminology, Techniques and Scoring System for Sleep stages in Human Subjects. Washington, D. C.: U. S. Government Printing office, 1968 .

Rechtschaffen, A. and Verdone, P. Amount of dreaming: Effect of incentive, adaptation to laboratory, and individual differences. Perceptual and Motor Skills, 1964, 19, 947-958.

Richardson, A. Mental Imagery. New York: Springer, 1969.

Salamy, J. Instrumental responding to internal cues associated with REM sleep. Psychonomic Science, $1970, \underline{18}, 342-343$.

- Effects of REM deprivation and awakening on instrumental performance during stage 2 and REM sleep. Biological Psychiatry, 1971, $\underline{3}, 321-330$.

Shollar, E. R. Modifying the sleep cycle: The effect of presleep instructions on the length of rapid eye movement sleep periods. Dissertations Abstracts International, $1975, \underline{36}(6-\mathrm{B}), 3014$.

Shorkey, C. and Himle, D. P. Systematic desensitization treatment of a recurring nightmare and related insomnia. Journal of Behavior Therapy and Experimental Psychiatry, 1974, 5, 97-98.

Silverman, I. and Geer, J.H. The elimination of a recurrent nightmare by desensitization of a related phobia. Behavior Research and Therapy, 1968, $\underline{6}$, 109-111.

Starker, S. Aspects of inner experience: Autokinesis, daydreaming, dream recall and cognitive style. Perceptual and Motor Skills, 1973, 36, 663-673. 
- Daydreaming styles and nocturnal dreaming: Further observations. Perceptual and Motor Skills, $1977,45,411-4 \overline{18}$.

Stewart, K. Mental hygiene and world peace. Mental Hygiene, $1954,38,387-403$.

The dream comes of age. Mental Hygiene, $1962,46,230-237$.

Dream theory in Malaya. In C. Tart (Ed.) Altered States of Consciousness. New York: Doubleday, 1972 .

Stoyva, J. M. Posthypnotically suggested dreams and the sleep cycle. Archives of General Psychiatry, 1965, 12, 287-294.

Tart, C. T. A comparison of suggested dreams occurring in hypnosis and sleep. International Journal of Clinical and Experimental Hypnosis, 1964, 12, 263-289.

- Toward the experimental control of dreaming: A review of the literature. Psychological Bulletin, $1965, \underline{64}, 81-91$.

- Some effects of posthypnotic suggestion on the process of dreaming. International Journal of Clinical and Experimental Hypnosis, 1966, 14, $30-46$.

Tart, C. T. and Dick, L. Conscious control of dreaming: I. The posthypnotic dream. Journal of Abnormal Psychology, 1970, 76, 304-315.

Walker, P. C. and Johnson, R. F. Q. The influence of presleep suggestions on dream content: Evidence and methodological problems. Psychological Bulletin, 1974, 81, 362-370.

Weinberg, H. Evidence suggesting the acquisition of a simple discrimination during sleep. Canadian Journal of Psychology, 1966, 20, 1-11.

Williams, H. L., Morlock, H. C. and Morlock, J. V. Instrumental behavior during sleep. Psychophysiology, $1966, \underline{2}, 208-216$.

Zung, W. W. K. and Wilson, W. P. Response to auditory stimulation during sleep. Archives of General Psychiatry, 1961, $\underline{4}, 548-552$. 


\section{APPENDIX A}

\section{SLEEP AND DREAM-HABITS QUESTIONNAIRE}

Please answer each of the following questions as accurately as you can. All of the information you provide will be kept strictly confidential and will be used only for purposes of this research project.

Name:

\section{Last First}

Address :

\section{Street City}

Phone:

Age : Sex: Male _ Female

For each of the following questions, indicate your answer by placing a cross $(X)$ on one of the provided blanks.

1. Do you sleep alone in your bed? Yes No

2. Do you sleep alone in your room? Yes No

3. Are you presently using any prescribed medication? Yes No

4. Once you are in bed and ready to sleep, about how many minutes does it take you to fall asleep?

$$
\begin{aligned}
& \text { less than } 5-5-10-10-15-15-20- \\
& \text { more than } 20
\end{aligned}
$$

5. About how many hours do you sleep each night? less than $5-{ }^{5-6}-{ }^{7-8}-{ }^{9-10}$ - more than 10 - 
6. Do you have a regular bedtime and waking time?

$$
\text { Yes }
$$

No

7. At approximately what time do you usually go to sleep?
9 P.M.
10 P.M.
11 P.M.
12 A.M.
1 A.M.

8. At approximately what time do you usually get up each morning?
6 A.M.
7 A.M.
8 A.M.
9 A.M.
10 A.M.

9. During the LAST TWO WEEKS, immediately upon waking up in the morning, how often do you recall having been dreaming?

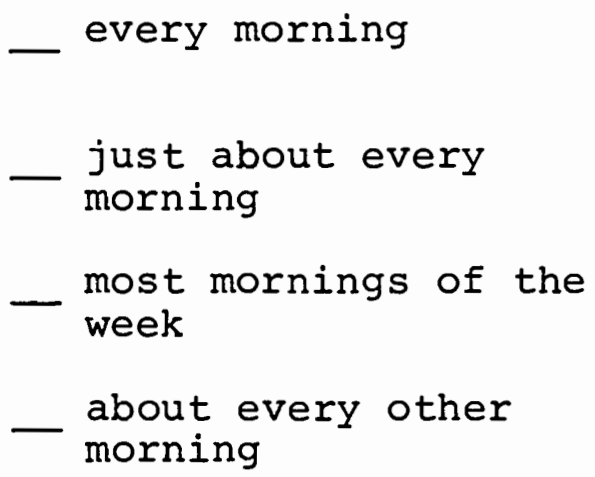

10. During the LAST TWO WEEKS, how often did you record (tape recorded or written) the dreams you recalied?

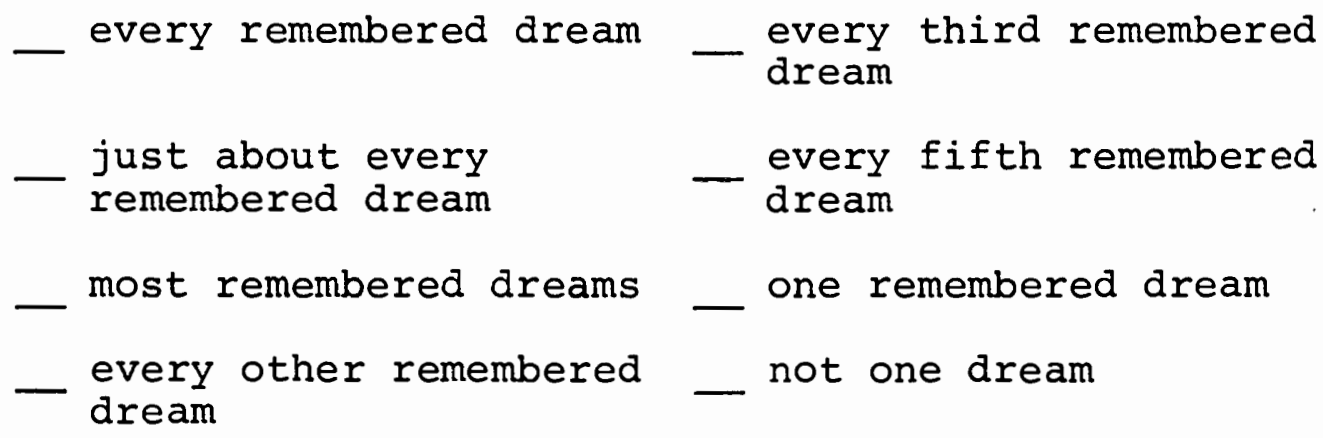

11. How clearly do you remember your dreams? not at all a few parts many parts most parts in great detail 
12. Do you find it dificult to fall asleep in new surroundings?

Yes No

13. Are you able to get your typical night of sleep when in new surroundings? Yes No

14. How interested are you in dreams?

not at all a little moderately extremely

15. How interested are you in participating in this dream research project?

not at all a little moderately extremely

16. Have you ever been able to dream about something you wanted to dream about? Yes _ No __ If you answered yes, approximately how many times do you remember this happening?

17. While asleep and dreaming, have you ever been able to direct the content of your dream? (In other words, while dreaming were you aware you were dreaming and able to change what you were dreaming about?)

Yes No If you answered yes, approximately how many times do you remember this happening?

18. Do you think it is possible to control the content of dreams (to dream what you want to dream about)? Yes No 
19. Which of the following books on dreaming have you read? Book Author

The Interpretation of Dreams Sigmund Freud

Creative Dreaming

Patricia Garfield

Dream Power

Ann Farraday

The Dream Game

Ann Farraday

Altered States of

Consciousness

Charles Tart

The Dream Makers

Richard Corriere \& Joseph Hart

Other books:

20. If there is anything else you would like to tell me about your dreams and/or dreaming habits, feel free to do so here: 
APPENDIX B

THE BETTS QMI VIVIDNESS OF IMAGERY SCALE

The aim of this test is to determine the vividness of your imagery. The items of the test will bring certain images to your mind. You are to rate the vividness of each image by reference to the accompanying rating scale which is attached to this page. For example, if your image is "vague and dim", you give it a rating of 5 . Record your answer in the brackets provided after each item. Just write the appropriate number after each item. Before you turn to the items on the next page, detach the rating scale and familiarize yourself with the different categories on the scale. Keep this rating scale available, and throughout the test, refer to it when judging the vividness of each image. Please do not turn to the next page until you have completed the items on the page you are doing and do not turn back to check on other items you have done. Complete each page before moving on to the next page. Try to do each item separately, independent of how you may have done other items.

An example of an item on the test would be one which asked you to consider an image which comes to your mind's eye of a red apple. If your visual image was "moderately 
clear and vivid", you would check the rating scale and mark " 3 " in the brackets as follows:

\section{Item \\ Rating}

5. A red apple

Now turn to the next page when you have understood these instructions and begin the test. 


\section{Rating Scale}

The image aroused by an item of this test may be:

Perfectly clear and as vivid as the actual experience

$\underline{\text { Rating } 1}$

Very clear and comparable to

vividness to the actual experience Rating 2

Moderately clear and vivid

Rating 3

Not clear or vivid

Rating 4

Not clear or vivid, but

recognizable

Rating 5

Vague and dim

Rating 6

So vague and dim as to be hardly recognizable

Rating 6

No image present at all, you only

"knowing" that you are thinking

of the object

Rating 7 
Think of some relative or friend whom you frequently see, considering carefully the picture that rises before your mind's eye. Classify the images suggested by each of the following questions as indicated by the degrees of clearness and vividness specified on the Rating Scale.

Item Rating

1. The exact contour of face, head, shoulders and body

2. Characteristic poses of head, attitudes of body, etc.

3. The precise carriage, length of step, etc., in walking

4. The different colors worn in some familiar costume

Think of seeing the following, considering carefully the picture which comes before your mind's eye, and classify the image suggested by the following question as indicated by the degree of clearness and vividness specified on the Rating Scale

5. The sun as it is sinking below the horizon 
Think of each of the following sounds, considering carefully the image which comes to your mind's ear, and classify the images suggested by each of the following questions as indicated by the degrees of clearness and vividness specified on the Rating scale.

I tem

Rating

6. The whistle of a locomotive

7. The honk of an automobile

8. The mewing of a cat

9. The sound of escaping steam

10. The clapping of hands in applause 
Think of "feeling" or touching each of the following, considering carefully the image which comes to your mind's touch, and classify the images suggested by each of the following questions as indicated by the degrees of clearness and vividness specified on the Rating Scale.

Item

11. Sand

12. Linen

13. Fur

14. The prick of a pin

15. The warmth of a tepid bath
Rating
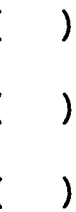

$(\quad)$

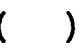


Think of performing each of the following acts, considering carefully the image which comes to your mind's arms, legs, lips, etc., and classify the images suggested as indicated by the degrees of clearness and vividness specified on the Rating Scale.

Item

16. Running upstairs

17. Springing across a gutter

18. Drawing a circle on paper

19. Reaching up to a high shelf

20. Kicking something out of your way
Rating
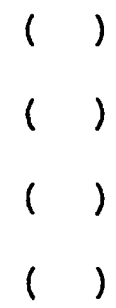

) 
Think of tasting each of the following, considering carefully the image which comes to your mind's mouth, and classify the images suggested by each of the following questions as indicated by the degrees of clearness and vividness specified on the Rating scale.

Item

Rating

21. Salt

22. Granulated (white) sugar

23. Oranges

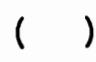

24. Jelly

25. Your favorite soup 
Think of smelling each of the following, considering carefully the image which comes to your mind's nose, and classify the images suggested by each of the following questions as indicated by the degrees of clearness and vividness specified on the Rating Scale.

Item

26. An ill-ventilated room

27. Cooking cabbage

28. Roast beef

29. Fresh paint

30. New leather
Rating

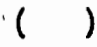

( )
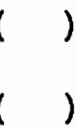

( ) 
Think of each of the following sensations, considering carefully the image which comes before your mind, and classify the images suggested as indicated by the degrees of clearness and vividness specified on the Rating Scale.

Item

31. Fatigue

32. Hunger

33. A sore throat

34. Drowsiness

35. Repletion as from a very full meal
Rating
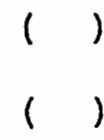

$($ )

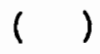

$(1)$ 


\section{APPENDIX C}

\section{THE GORDON TEST OF VISUAL IMAGERY CONTROL}

The questions on this form are concerned with the ease with which you can control or manipulate visual images. For some people this task is relatively easy and for others relatively hard. One subject who could not manipulate his imagery easily gave this illustration. He visualized a table, one of whose legs suddenly began to collapse. He then tried to visualize another table with four solid legs, but found it impossible. The image of the first table with its collapsing leg persisted. Another subject reported that when he visualized a table the image was rather vague and dim. He could visualize it briefly but it was difficult to retain by any voluntary effort. In both these illustrations the subjects had difficulty in controlling or manipulating their visual imagery. It is perhaps important to emphasize that these experiences are in no way abnormal and are as often reported as the controllable type of image.

Read each question, then close your eyes while you try to visualize the scene described. Record your answer by underlining "Yes", "No", or "Unsure", whichever is the most appropriate. Remember that your accurate and honest 
answer to these questions is most important for the validity of this study. If you have any doubts at all regarding the answer to a question, underline "Unsure". Please be certain that you answer each of the twelve questions.

Now turn to the next page and begin. 
1. Can you see a car standing in

the road in front of a house?

Yes No Unsure

2. Can you see it in color?

Yes No Unsure

3. Can you now see it in a

different color?

Yes No Unsure

4. Can you now see the same car

lying upside down?

Yes No Unsure

5. Can you now see the same

car back on its four

wheels again?

Yes No Unsure

6. Can you see the car

running along the road?

Yes No Unsure

7. Can you see it climb

up a very steep hill?

Yes No Unsure

8. Can you see it climb over

the top?

Yes No Unsure

9. Can you see it get out of

control and crash through
a house?
Yes No Unsure

10. Can you now see the same

car running along the road

with a handsome couple inside? Yes No Unsure

11. Can you see the car cross a

bridge and fall over the side

into the stream below?

Yes No Unsure

12. Can you see the car ali old and dismantled in a car-cementary? Yes . No Unsure 
APPENDIX D

CONSENT FORM

I, (__ hereby agree to

serve as a subject in the research project on dream control being conducted by Gary Lehto (Graduate Student, Psychology). The experimental procedure and my role as a subject have been explained to me. I understand that I will need to attend three hours (two $1 \frac{1}{2}$ hour sessions) of classroom instruction/training, and I will also need to sleep for two consecutive nights in a sleep laboratory located at Portland State University. I understand that my sleep will be monitored through continuous recordings of my brain activity (EEG) and eye movements (EOG), and although I may find the electrode attachments necessary for these measures slightly uncomfortable, the procedure is not physically or psychologically harmful. I understand that my sleep in the laboratory will be periodically interrupted, and I will be asked to honestly report whatever dreams or thoughts were in my mind prior to the awakening. It has been pointed out to me that this project is not designed to assess my psychological functioning, and I will not be forced to disclose any information I do not wish to. 
I understand that the purpose of this study is to obtain information on the relationship between waking and sleep cognition, especially mentation occurring during rapid eye movement ( $R E M)$ sleep. I have been told that a more detailed explanation of the study will be available to me after I have completed my work as a subject.

I may not receive any direct benefit from participation in this study, but my involvement may help to increase knowledge in the area of dreaming and may possibly benefit others in the future.

Gary Lehto has informed me that protecting my safety and integrity are his foremost concerns.

I understand that I am free to withdraw from participation in this study at any time without jeopardizing my relationship with Portland State University.

I have read and understood all of the above inFormation.

Date Signature

If you experience any problems that are the result of your participation in this study, please contact Richard Streeter, Office of Graduate Studies and Research, 105 Neuberger Hall, Portland State University, 229-3423. 


\section{APPENDIX E \\ SELF-INSTRUCTION SEQUENCE}

The self-instruction sequence was presented as a waking-state exercise on content control, and subjects were asked to practice and learn this sequence. The purpose of the sequence was to focus attention on the task of controlling dream content; aid in the acquisition of dream or dream-like imagery as a stimulus cue for further, directed imagery of a desired dream topic; and to facilitate the storage of this information in short and long-term memory. The sequence is outlined below and the amount of time spent on each portion of it is parenthetically noted.

A. Self-In'truction (20-40 seconds)

1. Firstly, a "set" statement was used to focus on the sequence task. Example: "I'll take my time and think clearly about what it is I have to do."

2. Following the set statement, a task relevant thought was used to prepare for imagery. Example: "Okay, I need to imagine a scene as clearly and vividly as possible, and this will be a signal for me that I need to direct my dream." 
B. Cuing Imagery (1-2 minutes)

The subject was to imagine a scene unrelated to the desired dream topic or imaginal reinforcer. Whenever possible, subjects were encouraged to use recurring dreams or at least a dream recalled in great detail.

C. Self-Instruction (5-10 seconds)

This was an acknowledgement of the imagery as a cue to change to the desired dream topic. Example: "Dream. Change to my topic."

D. Dream Imagery (2-3 minutes) The dream topic or desired dream is imagined.

E. Self-Reinforcement (30 seconds)

An imaginal reinforcer was presented immediately after the desired topic had been clearly and vividly imagined. A verbal reinforcer could also be used here. Verbal example: "Fantastic! This takes some time, but my dream imagery is becoming clearer." 


\section{APPENDIX F}

\section{DREAM TOPICS}

Five semantically different dream topics were used in order to enhance recognition of the assigned topics from the dream reports. These topics were obtained from a larger list of 20 common topics which had either been used in other content research or were devised on the basis of the common occurrence of a content area (Lindzey, Hall \& Thompson, 1978). This original list was given to 27 students in an undergraduate psychology class at Portland State University. These students were instructed to imagine dreaming of the topic and then to rate it on a shortened form of the semantic differential (Osgood, 1952). This shortened version contained 16 scales, 6 of which had been found to load highly on an evaluative factor, 6 on a potency factor, and 4 on an activity factor (Osgood \& Succi, 1955). Factor means were computed for each dream topic and the five found to be the most separated in semantic space were the following: 


$$
\text { Topic }
$$

Factor Means

$$
\text { Evaluative Potency Activity }
$$

1. Climbing Trees

$$
3.11
$$

2.73

2.86

2. Being Locked in

$$
\text { Jail }
$$

3. Finding Money

6.38

3.56

5.44

4. Floating in Water

5. Fighting in a War
2.54

2.78

6.36
3.97

4.42

2.53
2.87

4.26

3.69 


\section{APPENDIX G}

AWAKENING AND REPORT PROCEDURE

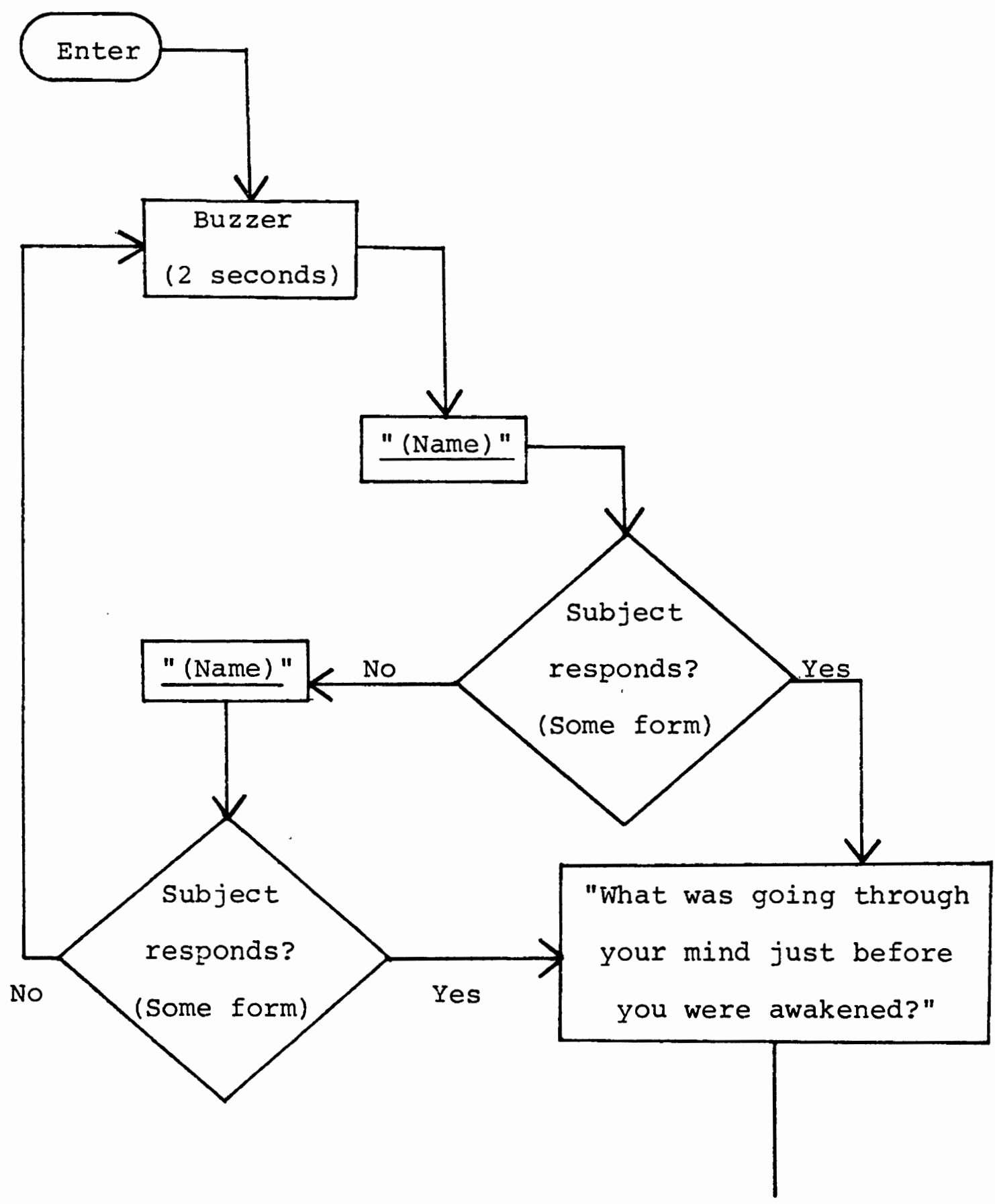




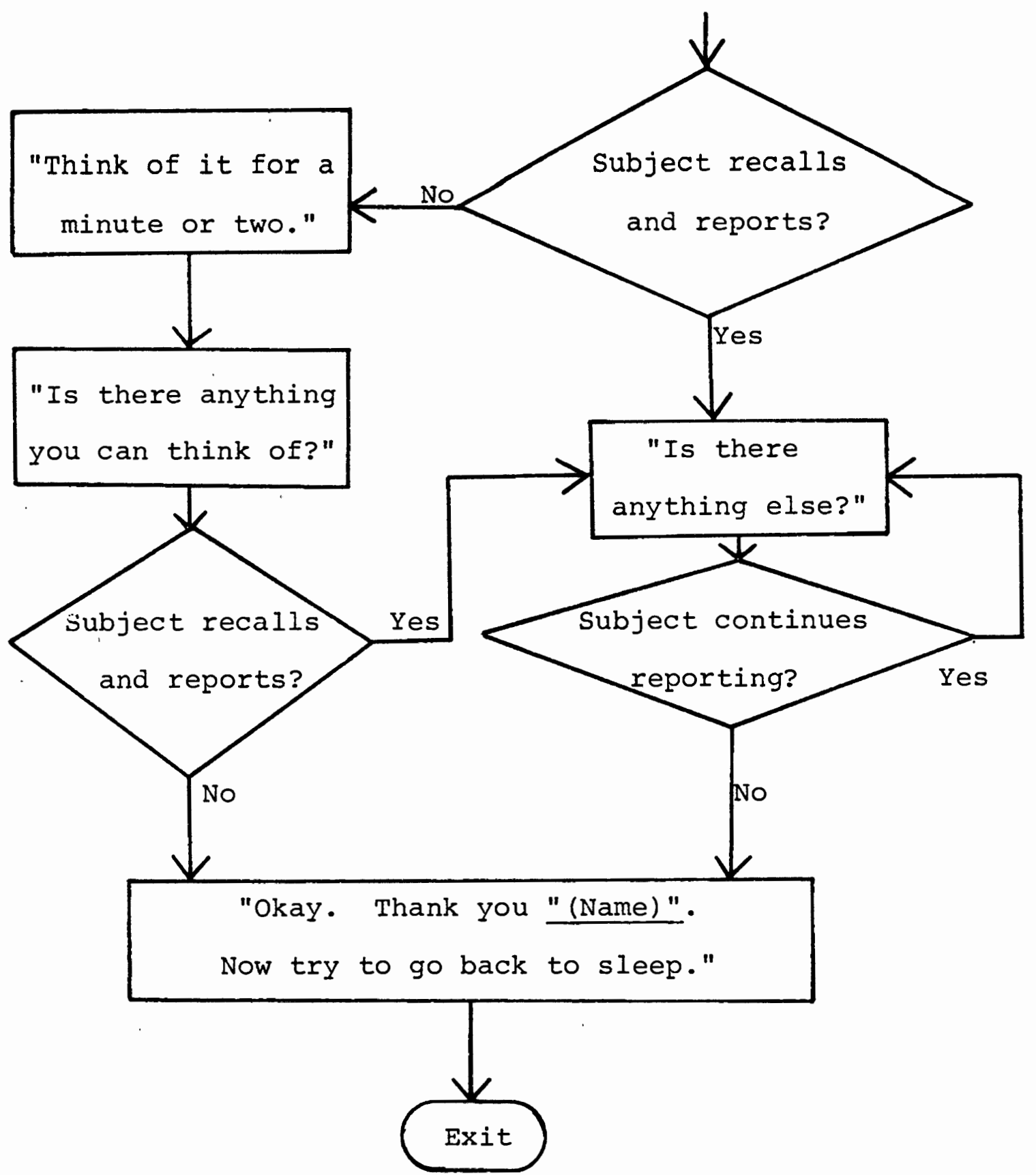


APPENDIX H

POSTSLEEP QUESTIONNAIRE

1. How well did you sleep last night?

Extremely Bad Poor Average Good Excellent

2. Before going to sleep last night, how much confidence did you have that you would be able to dream on the assigned topic?

None At All A Little A Fair Amount Much Very Much

3. How much success do you think you had in dreaming on the assigned topic?

None At All A Little A Fair Amount Much Very Much

4. What was your aream topic? (Put it into the form of the autosuggestion you were given.)

5. How much pleasure did you find in your dream topic? None At All A Little A Fair Amount Much Very Much

6. Before going to sleep at the beginning of the night, to what extent did you attempt to control or influence your dreams to dream on the assigned topic?

Not At All A Little A Fair Amount Much Very Much 
7. After giving a dream report and being told to try to go back to sleep, what was the average extent of your attempts to control or influence your dreams to dream on the assigned topic?

Not At All A Little A Fair Amount Much Very Much

8. Before going to sleep at the beginning of the night, about how many minutes would you say you spent thinking about the assigned topic? minutes

9. After giving a dream report and being told to go back to sleep, what would you say was the average amount of time you spent thinking about the assigned dream topic? minutes

10. During the LAST TWO WEEKS, immediately upon waking up in the morning, how often do you recall having been dreaming?

$\begin{array}{ll}\text { _ every morning } & -\begin{array}{l}\text { about two mornings } \\ \text { a week }\end{array} \\ \begin{array}{l}\text { just about every } \\ \text { morning }\end{array} & -\begin{array}{l}\text { about one morning } \\ \text { each week }\end{array} \\ \begin{array}{l}\text { most mornings of } \\ \text { the week } \\ \text { about every other } \\ \text { morning }\end{array} & \quad-\begin{array}{l}\text { once during the } \\ \text { two weeks }\end{array} \\ \end{array}$

11. How well do you think the training you received prepared you for controlling the content of your dreams? 
Not At All A Little A Fair Amount Much Very Much

12. Comments : 


\section{APPENDIX I}

SCORING PROCEDURE

I. Dream Topic Identification

Topics :

1. Climbing Trees

2. Being Locked in Jail

3. Finding Money

4. Floating in water

5. Fighting in a war

II. Degree of Content Control

A. Topic References

0 points - no reference to the topic

1 point - indirect reference(s) to verb or object

2 points - direct reference(s) to verb or object

3 points - direct reference(s) to verb or object and indirect reference(s) to either the verb or object not directly mentioned

4 points - direct references to both verb and object 
B. Personal Involvedness

0 points - not involved in any activity while observing topic action

1 point - not involved in topic action but engaged in some other activity while observing this action

2 points - personally involved in topic action

c. Shift in Content

1 point - no content changes or a shift away from topic

2 points - a shift from some content area to dream topic

III. Reason for Choice

letter 0 - direct and/or indirect reference(s) to object

letter V - direct and/or indirect reference(s) to verb

letter S - atmosphere, expressed feelings, situation, etc., suggestive of topic

letter G - "none of the above" (Topic could not be determined from the report so I just guessed.)

IV. Dream-Like Quality

0 points - no recall

1 point - not a dream (a non-perceptual report) 
2 points - a single image described in moderate detail

3 points - two images described in moderate detail with a story connecting them, or one image with great detail

4 points - two images in great detail, connecting story, and some bizarreness; or more than two images in moderate detail, connecting story, and some bizarreness

V. Multiplicative Combination

This measure was computed by the experimenter: Multiplicative Combination Score $=$

(Topic Reference Score) $x$ (Shift in Content Score) (Range: $0-8$ points) 


\section{APPENDIX J}

\section{TOPIC MEANS OF THE PLEASANT-UNPLEASANT SCALE OF THE SEMANTIC DIFFERENTIAL}

The pleasant-unpleasant scale ratings made by the same 27 students used in selecting the dream topics were also examined for the five topics utilized in this study. This particular scale loads highly on the evaluative factor of the semantic differential (Osgood \& Succi, 1955). Values on the scale can vary from 1 to 7 points with the higher scores indicating more unpleasantness. The means for the 27 students were calculated for each of the topics and are presented below:
1. Climbing Trees
2.68
2. Being Locked in Jail 6.44
3. Finding Money
2.12
4. Floating in Water
2.64
5. Fighting in a War
6.32 